\title{
Diverse Mechanisms of Sulfur Decoration in Bacterial tRNA and Their Cellular Functions
}

\author{
Chenkang Zheng ${ }^{1}$, Katherine A. Black ${ }^{2, *}$ and Patricia C. Dos Santos ${ }^{1, *}$ \\ 1 Department of Chemistry, Wake Forest University, Winston-Salem, NC 27101, USA; zhenc13@wfu.edu \\ 2 Weill Cornell Medical College, New York City, NY 10065, USA \\ * Correspondence: kab2824@med.cornell.edu (K.A.B.); dossanpc@wfu.edu (P.C.D.S.); \\ Tel.: +1-336 404-3814 (K.A.B.); +1-336-758-3144 (P.C.D.S.)
}

Academic Editor: Valérie de Crécy-Lagard

Received: 6 February 2017; Accepted: 16 March 2017; Published: 22 March 2017

\begin{abstract}
Sulfur-containing transfer ribonucleic acids (tRNAs) are ubiquitous biomolecules found in all organisms that possess a variety of functions. For decades, their roles in processes such as translation, structural stability, and cellular protection have been elucidated and appreciated. These thionucleosides are found in all types of bacteria; however, their biosynthetic pathways are distinct among different groups of bacteria. Considering that many of the thio-tRNA biosynthetic enzymes are absent in Gram-positive bacteria, recent studies have addressed how sulfur trafficking is regulated in these prokaryotic species. Interestingly, a novel proposal has been given for interplay among thionucleosides and the biosynthesis of other thiocofactors, through participation of shared-enzyme intermediates, the functions of which are impacted by the availability of substrate as well as metabolic demand of thiocofactors. This review describes the occurrence of thio-modifications in bacterial tRNA and current methods for detection of these modifications that have enabled studies on the biosynthesis and functions of S-containing tRNA across bacteria. It provides insight into potential modes of regulation and potential evolutionary events responsible for divergence in sulfur metabolism among prokaryotes.
\end{abstract}

Keywords: tRNA; thionucleoside; 2-thiouridine; 4-thiouridine; 2-methylthioadenosine; cysteine desulfurases; thiouridylase; thiocofactor

\section{Introduction}

Transfer ribonucleic acid (tRNA) is an essential facilitator in shuttling the genomic information between DNA and proteins. Nucleotide monomers consist of a ribose sugar, a phosphate group, and one of four different bases: adenine, uracil, cytosine, and guanine. These nucleotides can be post-transcriptionally modified to provide RNA with expanded chemical functionalities and afford diverse biological functions. Such chemical alterations have also been observed and studied mostly on ribosomal RNA (rRNA) and some messenger RNA (mRNA) [1-3]. More than 100 RNA modifications have been discovered thus far, and the majority are found within tRNA molecules [3-6]. Most of these "decorations" are derived from methylation, thiolation, and other more complex hypermodifications [7]. For example, pseudouridine $(\Psi)$, a modification so abundant that it was identified as a "fifth nucleoside" in RNA, is an isomerization product resulting in a C-C rather than a N-C glycosyl bond of uridine which links between the base and sugar [8]. Nucleoside thiolation is another widely occurring modification (Figure 1), including products such as 4-thiouridine ( $\left.\mathrm{s}^{4} \mathrm{U} 8\right), 2$-thiouridine derivatives $\left(\mathrm{xm}^{5} \mathrm{~s}^{2} \mathrm{U} 34\right), 2$-thiocytidine $\left(\mathrm{s}^{2} \mathrm{C} 32\right), 2$-methylthio- $N^{6}$-isopentenyladenosine $\left(\mathrm{ms}^{2} \mathrm{i}^{6} \mathrm{~A} 37\right)$ or 2-methylthio- $N^{6}$-threonylcarbamoyladenosine $\left(\mathrm{ms}^{2} \mathrm{t}^{6} \mathrm{~A} 37\right)$ and 2-thiouridothymidine $\left(\mathrm{s}^{2} \mathrm{~T} 54\right)$ in thermophiles (Figure 2) $[9,10]$. Thionucleosides are often formed by replacing the keto-oxygen on the base with sulfur [11,12], the exception being for that of thiolated adenines, which are modified 
with a methylthio-group originating from S-adenosyl-L-methionine (SAM) and a sulfur source that is not yet fully agreed upon [13-17]. These sulfur decorations are located throughout the tRNA "L-shaped" tertiary structure (Figure 1) and are important for maintaining proper tRNA conformation and functions. Typically, the functions of given tRNA modifications can be predicted based on their locations within the tertiary structure. Modifications occurring within the anticodon stem loop generally serve a role in translational accuracy and/or efficiency [18-21], while those located within the acceptor stem, the T-loop and the D-loop often function to maintain structural stability [19,22-24], or to serve as a recognition element for the appropriate tRNA aminoacyl synthetase and/or certain modification enzymes [24-27].

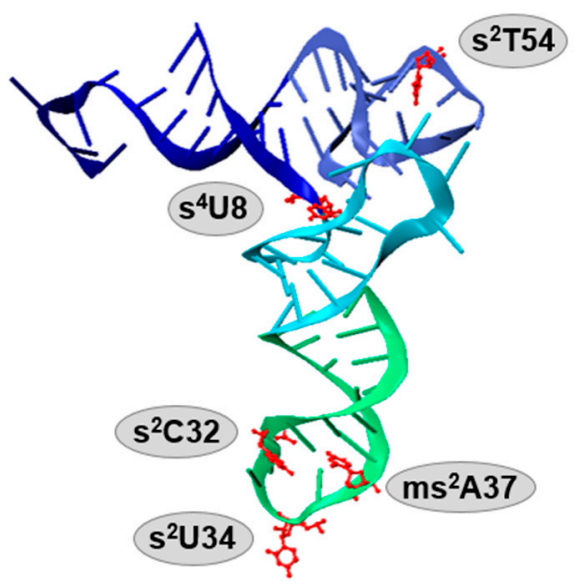

Figure 1. Location of thio-modifications in transfer ribonucleic acid (tRNA). The structure of a tRNA ${ }^{\text {Gln }}$ transcript (4jxz) with the positions of modified thionucleotides (red) was obtained in complex with Escherichia coli glutaminyl-tRNA synthetase (GlnRS) (not shown). The tRNA backbone and other nucleotides are colored by regions within which they are located on the tRNA as follows: The conserved CCA sequence to which amino acids are attached at the $3^{\prime}$ end is shown in navy, acceptor stem in royal blue, the D-loop in cyan, the anticodon loop in green, and the T-loop in periwinkle. It is important to note that in this isoacceptor, only positions 34 and 37 carry thionucleotides, and that this figure means to represent the locations of such modifications within a tRNA tertiary structure, rather than accurate information about a specific isoacceptor.

Although thio-modifications are present and retain a variety of functions in all three domains of life, in this review, we focus specifically on their biosynthesis and functions in bacteria, which can vary remarkably between Gram-positive and negative microbes. The occurrence of these modifications as well as the mechanisms governing their biological formation have been enabled through development of methods for detection and quantification of nucleoside modifications in biological samples and in biochemical in vitro reactions. We provide here a comprehensive summary of the available techniques for tRNA isolation and characterization, and highlight the coordination between modification positions within the tRNA structure and their corresponding functions.

\subsection{Anticodon Stem Loop Modifications}

tRNA acts as an adapter molecule between the nucleic acid blueprint and the protein product by bringing amino acids to the ribosome for incorporation into a growing peptide. Thus, it is intuitive that modifications altering the structure and/or reactivity of this biomolecule would have a direct impact on the translational process. Particularly, modifications located in or around the anticodon, such as those at the wobble position 34, as well as positions 32, and 37, generally serve to alter translation, and commonly increase translational accuracy by preventing the occurrence of frameshifting [6,28-34].

It is generally accepted that 20 universal amino acids are decoded by 61 combinations of triplet codons, in which case, one amino acid could be translated by more than one triplet codon. The first 
two base pairs in the mRNA codon are usually Watson-Crick paired with nucleotides 36 and 35 in the tRNA anticodon, while the third base can wobble to pair with other nucleotides of mRNA by means of nonstandard interactions [35,36]. Multiple modifications, including methylation and/or thiolation, can occur on position 34 of tRNA to ensure not only specificity, but also flexibility to discriminate multiple codons (Figure 2, Table 1). For instance, the bulky 2-thiocarbonyl group of $\mathrm{xm}^{5} \mathrm{~s}^{2} \mathrm{U}$ flips the $2^{\prime}$-hydroxyl ribose group and fixes the sugar into the $\mathrm{C} 3$ '-endo structure, locking its interactions to purines and preventing misreading and frameshifting events $[9,35]$. The thiol group of $\mathrm{xm}^{5} \mathrm{~s}^{2} \mathrm{U}$ also serves as an identity element for certain tRNA synthetases and enhances codon recognition in the ribosome [31,35,37-39].

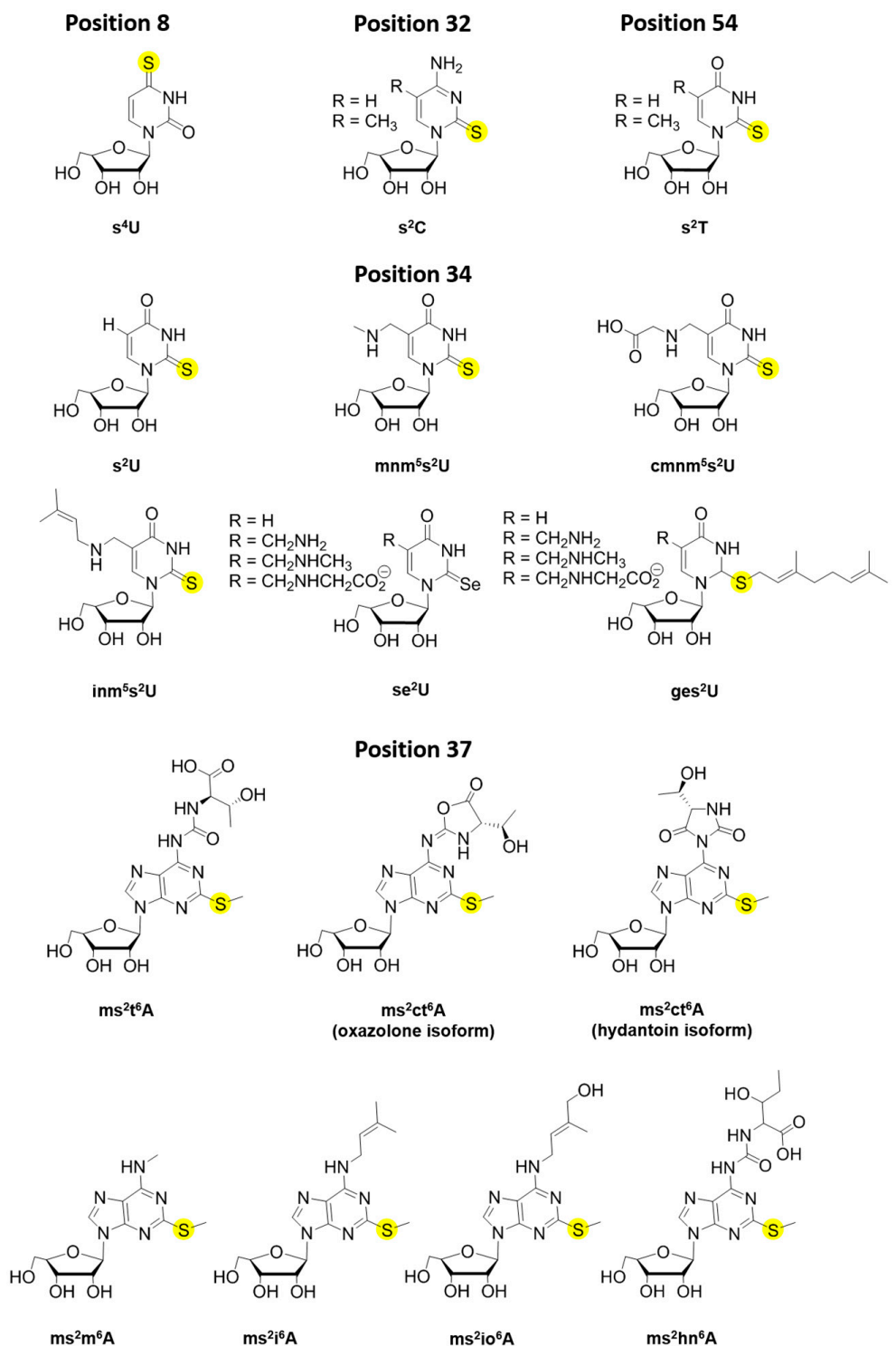

Figure 2. Structures of bacterial tRNA thionucleosides and their derivatives. The structures of the thionucleosides occurring in bacterial tRNA at positions 8, 32, 34, 37 and 54 are shown along with their hypermodified derivatives, with the sulfur atom highlighted in yellow. The structures of 2-geranylthiouridine ( ges $^{2} \mathrm{U}$ ) and 2-selenouridine ( $\left.\mathrm{se}^{2} \mathrm{U}\right)$, whose biosynthesis relies on U34 thiolation, as described in Table 1, are also depicted along with their derivatives. $\mathrm{mnm}^{5} \mathrm{~s}^{2} \mathrm{U}, \mathrm{cmnm}^{5} \mathrm{~s}^{2} \mathrm{U}$, and inm ${ }^{5} \mathrm{~s}^{2} \mathrm{U}$ may be methylated at $2^{\prime} \mathrm{OH}$. The cyclic form of $\mathrm{t}^{6} \mathrm{~A} 37$ was first hypothesized to exist in the oxazolone isoform, however, further investigation has revealed that it actually exists in the hydantoin isoform. 
Thiolation of U34 serves a variety of functions in eukaryotes [24,40]. In yeast, wobble uridine thiolation is sensitive to nutrient availability, and when sulfur-containing amino acids are limiting, $s^{2} U$ levels are depleted. This downregulates many processes involved in growth and metabolism, the components of which are encoded by genes enriched in codons read by thiolated uridines [41]. Absence of $s^{2} U$ showed development defects in eukaryotic model species [42,43]. In humans, mutations within $s^{2} U$ biosynthetic genes are associated with acute infantile liver failure and respiratory defects that lead to dysfunction of the auditory system. Furthermore, depletion of $s^{2} U$ in humans can lead to mitochondrial encephalopathies, causing epilepsy, ataxia, and dementia [44-49]. Interestingly, eukaryotes utilize two distinct pathways for $\mathrm{s}^{2} \mathrm{U}$ biosynthesis in the cytoplasm and the mitochondria, in which only the latter is evolutionarily related to the pathway for this modification in bacteria $[24,50,51]$. Not surprisingly, bacteria with deficiencies in $\mathrm{s}^{2} \mathrm{U}$ biosynthesis also exhibit severe growth defects [11,52-54].

Modifications at position 37 are proposed to tune the stability of codon-anticodon interactions. Recent work has identified a connection between $\mathrm{ms}^{2} \mathrm{t}^{6} \mathrm{~A} 37$ deficiency and type II diabetes due to inefficient and inaccurate translation of several proteins, including proinsulin $[55,56]$. This altered form of proinsulin is unable to be converted into insulin, leading to glucose intolerance. The impact of A37 modification deficiency on protein synthesis is further recognized by the mitochondrial translational defects resulting from absence of $\mathrm{ms}^{2} \mathrm{i}^{6} \mathrm{~A} 37$ in mice and humans, leading to cardiac dysfunction, accelerated myopathy and respiratory defects [57]. The relevance of tRNA modifications in human disease is intriguing, as they highlight the functional importance of these modifications on a grand scale and provide attractive targets for therapies in disease.

\subsection{Modifications within tRNA Body and Acceptor Stem}

Modifications found within the stem loops of the tRNA commonly affect tRNA structure, folding and stability, while modifications occurring at various positions ensure tRNA recognition by aminoacyl-tRNA synthetases [58,59]. These rules are applicable for most, if not all, tRNA modifications, and hold true for thio-modifications as well. $s^{4} U$, a well-studied photosensor of near-UV light, is a thionucleoside at the intersection of the tRNA acceptor- and D-arms that is highly conserved among bacterial species. When the cell is challenged by near-UV light, $\mathrm{s}^{4} \mathrm{U}$ forms a cross-link bond with cytosine 13, resulting in a shorter distance between acceptor arm and consequently disordering the D-loop and disordered "L"-shape of tRNA tertiary structure [60]. As the structurally changed tRNA becomes a poor substrate for aminoacylation, the cellular translational process is paused and cells enter the stringent response [61,62]. Only present in thermophiles, $\mathrm{s}^{2} \mathrm{~T}$ is found at position 54 on the TYC loop and stabilizes the overall tRNA structure at elevated temperatures $[9,40,63]$.

Table 1. Bacterial tRNA modifications whose biosynthesis relies on sulfur mobilization.

\begin{tabular}{|c|c|c|c|}
\hline \multicolumn{4}{|c|}{ Fe-S Cluster Independent Modifications } \\
\hline Modification & Name & Position & Biosynthetic Genes and Precursors \\
\hline $\mathrm{s}^{4} \mathrm{U}$ & 4-thiouridine & 8 & $\begin{array}{l}\text { iscS-thiI (Escherichia coli [11,62,64,65], Salmonella enterica [66] } \\
\text { and Thermatoga maritima [67]); or nifZ-thiI } \\
\text { (Bacillus subtilis [68] and Bacillus anthracis [69]) }\end{array}$ \\
\hline$s^{2} \mathrm{U}$ & 2-thiouridine & 34 & $\begin{array}{l}\text { iscS-tus } A B C D E-m n m A \text { (E. coli }[11,37,70,71] \text {, S. enterica, [52]); } \\
\text { or yrvO-mnmA (B. subtilis [72]) }\end{array}$ \\
\hline$m n m^{5} s^{2} U$ & $\begin{array}{l}\text { 5-methylaminomethyl- } \\
\text { 2-thiouridine }\end{array}$ & 34 & $\begin{array}{l}\mathrm{s}^{2} \mathrm{U}, m n m E G / g i d A, m n m C 1-2(\text { E. coli }[73]) ; \text { or s}^{2} \mathrm{U} \\
m n m E G / g i d A, m n m C 2 \text { (Aquifex aeolicus [74]) }\end{array}$ \\
\hline $\mathrm{cmnm}^{5} \mathrm{~s}^{2} \mathrm{U}$ & $\begin{array}{l}\text { 5-carboxymethylaminomethyl- } \\
\text { 2-thiouridine }\end{array}$ & 34 & $\mathrm{~s}^{2} \mathrm{U}, \mathrm{mnmEG/gidA}($ E. coli $[75-78])$ \\
\hline $\operatorname{inm}^{5} s^{2} U$ & $\begin{array}{l}\text { 5-(isopentenylaminomethyl)- } \\
\text { 2-thiouridine }\end{array}$ & 34 & $\begin{array}{l}\mathrm{nm}^{5} \mathrm{~s}^{2} \mathrm{U}, \text { unknown isopentenyltransferase } \\
\text { (Thermodesulfobacterium commune) }\end{array}$ \\
\hline $\mathrm{nm}^{5} \mathrm{~s}^{2} \mathrm{U}$ & 5-aminomethyl- 2-thiouridine & 34 & $\mathrm{~s}^{2} \mathrm{U}, m n m E G /$ gidA, mnmC1 (E. coli $\left.[73]\right)$ \\
\hline $\mathrm{se}^{2} \mathrm{U}$ & 2-selenouridine & 34 & $\mathrm{~s}^{2} \mathrm{U}$, selU/mnmH, selD (S. enterica [79] and E. coli [80]) \\
\hline $\mathrm{mnm}^{5} \mathrm{se}^{2} \mathrm{U}$ & $\begin{array}{l}\text { 5-methylaminomethyl- } \\
\text { 2-selenouridine }\end{array}$ & 34 & $\begin{array}{l}\mathrm{mnm}^{5} \mathrm{~s}^{2} \mathrm{U}, \text { selU } / \mathrm{mnmH}, \text { selD }(\text { S. enterica }[79,81,82] \text {, } \\
\text { E. coli }[80])\end{array}$ \\
\hline
\end{tabular}


Table 1. Cont.

\begin{tabular}{|c|c|c|c|}
\hline \multicolumn{4}{|c|}{ Fe-S Cluster Independent Modifications } \\
\hline Modification & Name & Position & Biosynthetic Genes and Precursors \\
\hline ges $^{2} \mathrm{U}$ & 2-geranylthiouridine & 34 & $\mathrm{~s}^{2} \mathrm{U}$, selU/mnmH (E. coli [83]) \\
\hline $\mathrm{cmnm}^{5} \operatorname{ges}^{2} \mathrm{U}$ & $\begin{array}{l}\text { 5-carboxymethylaminomethyl- } \\
\text { 2-geranylthiouridine }\end{array}$ & 34 & $\begin{array}{l}\mathrm{cmnm}^{5} \mathrm{~s}^{2} \mathrm{U} \text {, selU/mnmH (S. enterica [29,81], E. coli [29,83], } \\
\text { Enterobacter aerogenes, and Pseudomonas aeruginosa [29]) }\end{array}$ \\
\hline $\mathrm{mnm}^{5} \operatorname{ges}^{2} \mathrm{U}$ & $\begin{array}{l}\text { 5-methylaminomethy- } \\
\text { 2-geranylthiouridine }\end{array}$ & 34 & $\begin{array}{l}\mathrm{mnm}^{5} \mathrm{~s}^{2} \mathrm{U}, \text { selu/mnmH (S. enterica [29,81], E. coli [29,83], } \\
\text { E. aerogenes and P. aeruginosa [29]) }\end{array}$ \\
\hline $\mathrm{nm}^{5} \operatorname{ges}^{2} \mathrm{U}$ & $\begin{array}{l}\text { 5-aminomethyl- } \\
\text { 2-geranylthiouridine }\end{array}$ & 34 & $\mathrm{~nm}^{5} \mathrm{~s}^{2} \mathrm{U}$, proposed selU/mnmH (S. enterica and E. coli) \\
\hline$c t^{6} \mathrm{~A}$ & $\begin{array}{l}\text { cyclic } N^{6}- \\
\text { threonylcarbamoyladenosine }\end{array}$ & 37 & $\mathrm{t}^{6} \mathrm{~A}, \mathrm{tcdA} A \mathrm{cs} d \mathrm{~L}$ (E. coli $[59,84-87]$, B. subtilis [88]) \\
\hline $\mathrm{m}^{5} \mathrm{~s}^{2} \mathrm{U} / \mathrm{s}^{2} \mathrm{~T}$ & $\begin{array}{l}\text { 5-methyl-2- } \\
\text { thiouridine/2-thioribothymidine }\end{array}$ & 54 & $\begin{array}{l}\text { ttuBCA (Thermus thermophilus [10,89-92], } \\
\text { Pyrococcus furiosus [93]) }\end{array}$ \\
\hline \multicolumn{4}{|c|}{ Fe-S Cluster Dependent Modifications } \\
\hline Modification & Name & Position & Biosynthetic Genes and Precursors \\
\hline $\mathrm{s}^{2} \mathrm{C}$ & 2-thiocytidine & 32 & $\operatorname{ttc} A($ E. coli $[63,94])$ \\
\hline Q & queuosine & 34 & $\begin{array}{l}\text { folE, queACDEFG, tgt, (E. coli [95-102], S. enterica [95], } \\
\text { B. subtilis }[97,98,103,104], \text { Streptomyces rimosus [105], } \\
\text { Acinetobacter sp. and Zymomonas mobilis [106]) }\end{array}$ \\
\hline $\mathrm{m}^{2} \mathrm{~A}$ & 2-methyladenosine & 37 & $\operatorname{trm} G / r \operatorname{lm} N($ E. coli $[107,108])$ \\
\hline $\mathrm{ms}^{2} \mathrm{i}^{6} \mathrm{~A}$ & $\begin{array}{l}\text { 2-methylthio- } \\
N^{6} \text {-isopentenyladenosine }\end{array}$ & 37 & $\begin{array}{l}\text { i }^{6} \mathrm{~A}, \text { miaB }(\text { T. maritima }[13,15-17], \text { E. coli }[33,109] \text {, } \\
\text { S. enterica [33], Shigella flexneri }[110] \text { and B. subtilis }[111,112])\end{array}$ \\
\hline $\mathrm{ms}^{2} \mathrm{io}^{6} \mathrm{~A}$ & 2-methylthio- cis-ribozeatin & 37 & $\mathrm{~ms}^{2} \mathrm{i}^{6} \mathrm{~A}$, miaE (S. enterica $\left.[113,114]\right)$ \\
\hline $\mathrm{ms}^{2} \mathrm{t}^{6} \mathrm{~A}$ & $\begin{array}{l}\text { 2-methylthio- } N^{6} \text {-threonyl } \\
\text { carbamoyladenosine }\end{array}$ & 37 & $\mathrm{t}^{6} \mathrm{~A}$, yqeV/mtaB (B. subtilis $\left.[111,112]\right)$ \\
\hline $\mathrm{ms}^{2} \mathrm{ct}^{6} \mathrm{~A}$ & $\begin{array}{l}\text { 2-methylthio- cyclic- } N^{6} \text { - threonyl } \\
\text { carbamoyladenosine }\end{array}$ & 37 & $\mathrm{~ms}^{2} \mathrm{t}^{6} \mathrm{~A}, t c d A / c s d L$ (B. subtilis [88]) \\
\hline
\end{tabular}

\section{Methods for Investigation and Quantification of tRNA Modifications}

Analysis of in vivo tRNA modification levels using any of the detection methods described here first requires the isolation and purification of tRNA (or total RNA) from cultured cells and subsequent analysis either using full length tRNA or digested nucleosides. Here, we provide an overview of various methods used for isolation of tRNA from biological samples, and detection of sulfur-containing modifications (Table 2). In many cases, these methods can also be used in the analysis and quantification of other modifications to tRNA which are often used as denominators to determine the relative levels of thio-modifications or in assessing the cellular profile of certain protein expression (see discussion below).

Table 2. General methods for detection and analysis of tRNA modifications.

\begin{tabular}{ccll}
\hline Method & Target Modification & \multicolumn{1}{c}{ Advantage } & \multicolumn{1}{c}{ Disadvantage } \\
\hline Chemical labeling & $\begin{array}{c}\mathrm{s}^{2} \mathrm{U}, \mathrm{s}^{4} \mathrm{U}, \mathrm{mnm}^{5} \mathrm{~s}^{2} \mathrm{U}, \\
\text { pseudouridine }\end{array}$ & $\begin{array}{l}\text { Labeling only occurs in the } \\
\text { modified species; high selectivity }\end{array}$ & $\begin{array}{l}\text { Detection method varies with } \\
\text { modification and potential } \\
\text { side reactions }\end{array}$ \\
\hline Northern Blot & all & $\begin{array}{l}\text { High sensitivity towards specific } \\
\text { tRNA sequences }\end{array}$ & $\begin{array}{l}\text { Unable to differentiate modified and } \\
\text { canonical nucleotides; requires RNA } \\
\text { probe for each cognate tRNA; may } \\
\text { require radioactive probe }\end{array}$ \\
\hline Immuno-Northern Blot & $\mathrm{m}^{1} \mathrm{~A}, \mathrm{~m}^{6} \mathrm{~A}, \mathrm{~m}^{5} \mathrm{C}$ & $\begin{array}{l}\text { Antibodies bind specifically to the } \\
\text { modified nucleoside }\end{array}$ & Limited antibodies \\
\hline APM-gel & $\mathrm{s}^{4} \mathrm{U}, \mathrm{s}^{2} \mathrm{U}$ and derivatives & $\begin{array}{l}\text { Detect polynucleotides and single } \\
\text { nucleosides; simple analysis }\end{array}$ & $\begin{array}{l}\text { Hazardous mercury compound } \\
\text { involved; varied sensitivity toward } \\
\text { different thionucleotides }\end{array}$ \\
\hline
\end{tabular}


Table 2. Cont.

\begin{tabular}{ccll}
\hline Method & Target Modification & Advantage & Disadvantage \\
\hline APB-gel & Q & Specific to Q modification & $\begin{array}{l}\text { Reactive with cis-diol } \\
\text { functional groups }\end{array}$ \\
\hline HPLC-UV/vis & all & $\begin{array}{l}\text { Simple sample preparation and } \\
\text { data quantification. Certain } \\
\text { nucleosides have unique } \\
\text { absorbance } \lambda \text { max }\end{array}$ & Nuclease and phosphatase treatments \\
\hline HPLC-MS & all & High sensitivity and accuracy & $\begin{array}{l}\text { Detection may result of fragmentation } \\
\text { of certain modifications }\end{array}$ \\
\hline
\end{tabular}

APB: $N$-acryloyl-3-aminophenylboronic acid; APM: [(N-acryloylamino)phenyl]mercuric chloride; HPLC-UV: High Pressure Liquid Chromatography separation coupled to ultraviolet detection; HPLC-MS: High Pressure Liquid Chromatography separation coupled to Mass Spectrometry detection.

\subsection{Isolation of $t R N A$ from Biological Samples}

There are several methods reported for the isolation of tRNA adjusted to laboratory budget and scale. Thus, while methodologies vary between laboratories, the underlying principles remain constant. First, cells are lysed or homogenized using TRIzol (phenol, chloroform, guanidinium thiocyanate) with agitation, or mechanically, using a bead beater or French pressure cell in presence or absence of lysozyme. Denaturants such as phenol and chloroform, and chaotropic agents, like guanidinium thiocyanate, also quench biochemical processes during isolation, thereby maintaining RNA integrity. Commonly, cells are suspended in aqueous buffer prior to homogenization and subjected to separation between aqueous and organic phases. The use of acidic phenol $(\mathrm{pH} \sim 4.5)$ enables retention of RNA in the aqueous phase, while DNA is extracted into the organic phase. Once RNA is sufficiently isolated into the aqueous phase, it can be further purified using lithium chloride treatment which precipitates large RNA fragments, but not tRNA or small RNA fragments [115]. The resulting soluble material can be precipitated with isopropanol or ethanol, or retrieved with silica-based spin columns. While alcohol precipitation is certainly more cost-effective, yields are lower, and caution must be taken not to over or not sufficiently dry the resulting RNA pellet. Thus, although the RNA isolation process can be flexible, caution is advised to ensure efficient isolation of pure, high quality tRNA samples. This can be evaluated using UV absorbance, denaturing gel electrophoresis, or fluorescent dye-based electrophoresis [116].

Many studies require the purification of individual tRNA species, and advances in liquid chromatography (LC) techniques have streamlined this process as opposed to the cumbersome traditional methods involving gel electrophoresis. There are several chromatography techniques facilitating RNA purification including anion-exchange and ion-pair reverse phase chromatography [116]. Affinity-based approaches for purification of specific tRNA species make use of oligonucleotide probes designed to capture the tRNA isoacceptor of interest using a unique sequence complementary to that within the tRNA [117-119]. Though the presence and locations of modifications within tRNA species are not fully known across organisms, the genomic sequences encoding tRNAs are commonly available, and thus can be used for probe design. Affinity purification methods make it possible to isolate bulk amounts of a specific tRNA isoacceptor, which is particularly useful when assessing modification function by comparing structure and/or function of synthetic hypomodified tRNA to biologically isolated and thus, fully modified tRNA species.

In vitro transcription methods to generate synthetic tRNA transcripts enable efficient and robust production of a pure single tRNA isoacceptor. However, the products are completely devoid of modifications, and, in some cases, subsequent kinetic analysis of these transcripts can skew assay results away from physiological relevance. Recent reports have demonstrated that modifications not only modulate the structure and function of these adapter molecules, they also decorate tRNA molecules to mediate specificity in substrate recognition by their enzyme interacting partners. One example is that of a study in which Rodriguez-Hernandez et al. conducted an exhaustive structural and functional investigation of the role of sulfur in tRNA [6]. Aminoacylation and ribosome 
utilization in Escherichia coli was assessed when using synthetic unmodified tRNA transcripts and fully modified tRNA obtained via affinity purification. Structural work showed that hypermodified $\mathrm{tRNA}^{\mathrm{Gln}}$ induces conformational changes in glutaminyl-tRNA synthetase (GlnRS) which improve the conformation of a surface loop within the protein, and create a specific binding pocket for the 2-thio moiety. Aminoacylation kinetic analysis demonstrated that E. coli GlnRS had a 10-fold improvement in binding affinity for $t R N A^{\text {Gln }}$ containing $s^{2} U$ compared to unmodified $t R N A$ Gln , which was further improved five-fold with the addition of the $\mathrm{cmnm}^{5}$-modification. Furthermore, thiolated U34 tRNA improved binding affinity to Gln codons and demonstrated five-fold enhancement of GTP hydrolysis by E. coli EF-Tu (elongation factor thermo unstable) compared to the unmodified tRNA [6]. Together, these findings provide excellent examples of the effects of tRNA modifications on enzyme kinetics and highlight the importance of comparing results from methods using both synthetic and native tRNA molecules.

\subsubsection{Chemical Labeling}

Historically, chemical reagents have been used to selectively label modified nucleosides based on the chemical functionality of such modifications [120]. With the rise of mass spectrometry and other sensitive techniques, chemical labeling and modification conversion techniques remain useful as they provide improved detection and chemical stability for target analytes. Thiol groups are strong nucleophiles able to react with a wide range of reagents, including halo-acetamides $\left(s^{2} U, s^{4} U\right)$ [121], 4-bromomethyl-7-methoxy-2-oxo-2H-benzopyran (bromomethylcoumarin) [122], and 3-carboxy-2,2,5,5-tetramethyl pyrroline-1-oxyl anhydride with ethyl hydrogen carbonate $\left(\mathrm{mnm}^{5} \mathrm{~s}^{2} \mathrm{U}\right)$ [121]. Labeling and detection of other non-thiolated modifications has also been described in the literature. For example, isothiocyanate and activated amines (e.g., ethylenediamine) can covalently interact with the carboxyl group on $t^{6} \mathrm{~A}$ [123] and aliphatic amines can attack queuosine [124]. Although these reagents have specific selectivity towards target modifications, other modifications sharing similar functional groups can display cross-reactivity. For instance, in addition to bromomethylcoumarin's ability to target thiolated uridine [122], it also reacts with pseudouridine [125], and potentially with uridine and thymidine [126].

\subsubsection{Enrichment of Modified Nucleoside}

Thiophilic "soft" metal mercury reacts readily with sulfur-modified nucleic acids. Igloi and his colleagues in 1988 first introduced a synthetic [(N-acryloylamino)phenyl]mercuric chloride (APM), which can be co-polymerized into polyacrylamide gels to separate thiolated tRNA [127]. APM was further developed by the Biondi group into a three-layer polyacrylamide gel with only the middle layer containing a high amount of the organomercuric compound [128]. The formation of a coordinate covalent bond between $\mathrm{Hg}$ and $\mathrm{S}$ ligand retards the electrophoretic migration of thio-modified RNA. The results can be visualized by standard methods for polyacrylamide electrophoresis imaging, including fluorescence, silver or ethidium bromide staining. Although the APM-gel has proved to be a low-cost and effective detection method, different thiol-containing tRNAs have shown different migration patterns through the APM layer due to varying structures of the thionucleotide. The APM-gel up to date has shown a great ability to covalently link 4-thiouridine and 2-thiouridine and its derivatives. However, when the sulfur is not in the thiocarbonyl form, for instance, in $\mathrm{ms}^{2} \mathrm{i}^{6} \mathrm{~A}$ or $\mathrm{ms}^{2} \mathrm{t}^{6} \mathrm{~A}$ modifications, APM has not been found to covalently coordinate with these thio-modified nucleosides effectively [129]. Despite its low selectively towards different sulfur modifications in tRNA, APM gel separation is still one of the most commonly used detection and isolation methods for thiolated RNA.

Queuosine is a non-thiolated modification, but its biosynthesis depends on [Fe-S] clusters (Table 1). This modification can also be retained in a polyacrylamide gel containing a boronic acid derivative. The synthetic $N$-acryloyl-3-aminophenylboronic acid (APB), when co-polymerized into acrylamide gel, is able to retain cis-diol groups present in tRNA, like queuosine, resulting in separation of the cis-diol 
containing ribonucleic acid $[130,131]$. However, APB is not only able to separate queuosine, but any tRNA samples containing cis-diol, including RNA with non-phosphorylated $3^{\prime}$ ends [130] and the newly discovered bacterial nicotinamide adenine dinucleotide (NAD)-capped tRNA [132]. From both APM- and APB-gel detection, thionucleosides may be extracted and isolated for further quantification.

\subsubsection{Northern Blot}

Northern blot has been a valuable tool for probing individual tRNA species. Sequence specific hybridizing probes are usually modified with either radioisotope ${ }^{32} \mathrm{P}$ or fluorescent labels to improve detection sensitivity. Although radioactive-labeled probes are advantageous for improving detection sensitivity and assay quality, the disadvantage of such experiments is the need to minimize the usage of radioactive substances. This technique has also been used in conjunction with APM-containing polyacrylamide gels to identify the occurrence of thiolation on certain tRNA species [133-137]. Recently, a variation of the standard method, immuno-Northern blot, was provided which uses antibodies that specifically bind with modified nucleosides such as 1-methyladenosine ( $\left.\mathrm{m}^{1} \mathrm{a}\right), N^{6}$-methyladenosine $\left(m^{6} \mathrm{~A}\right)$, pseudouridine, and 5-methylcytidine $\left(\mathrm{m}^{5} \mathrm{C}\right)$ [138]. This highly sensitive and relatively simple protocol enables small laboratories to compare the abundance of modified nucleic acids across samples.

\subsection{Quantification of tRNA Modification Levels Using Liquid Chromatography}

Detection and quantification of tRNA modification levels using liquid chromatography (LC) is performed on nucleosides isolated from purified tRNA samples. In this case, bulk tRNA needs to be first digested into individual nucleotides using nuclease P1 or endonuclease Bal31 followed by treatment with phosphatase $[116,139,140]$. Individual nucleosides are then subjected to separation via reverse phase high pressure liquid chromatography (RP-HPLC). Commonly used protocols for digestion of tRNA involve sequential incubation with acidic and basic buffers for nuclease P1 and alkaline phosphatase, respectively. However, recent studies have reported that both acidic and basic reaction conditions lead to degradation of many labile modifications, such as $\mathrm{ct}^{6} \mathrm{~A}$ to $\mathrm{t}^{6} \mathrm{~A}$ and $\mathrm{ms}^{2} \mathrm{ct}^{6} \mathrm{~A}$ to $\mathrm{ms}^{2} \mathrm{t}^{6} \mathrm{~A}[59,87,88]$. Alternatively, this problem can be overcome by digestion at physiological $\mathrm{pH}$, and the use of endonucleases like benzonase, which is active at physiological pH [116].

\subsubsection{High Pressure Liquid Chromatography Separation Coupled to Ultraviolet-Visible Detection}

The absorption maxima of most nucleosides lies around $260 \mathrm{~nm}$. However certain modifications to the nitrogenous bases alter the physicochemical properties of specific nucleosides, resulting in distinct maximum absorption wavelength $\left(\lambda_{\max }\right)$ values, including for many thionucleosides $\left(\mathrm{s}^{2} \mathrm{U} \lambda_{\max }\right.$ $\left.\sim 280 \mathrm{~nm}, \mathrm{~s}^{4} \mathrm{U} \lambda_{\max } \sim 330 \mathrm{~nm}, \mathrm{~s}^{2} \mathrm{C} \lambda_{\max } \sim 245 \mathrm{~nm}, \mathrm{~ms}^{2} \mathrm{~A} \lambda_{\max } \sim 240 \mathrm{~nm}\right)[139,140]$. Therefore, RP-HPLC coupled to UV-Visible detection, particularly with a diode array detector, has been extremely useful in past decades for quantification of such modifications. For this analysis, C18 columns are used to separate nucleosides starting with a high percentage $(98 \%-100 \%)$ of aqueous solvent to elute the most polar nucleosides, followed by a gradient of organic solvent, such as acetonitrile or methanol to elute those with more hydrophobic properties. Considering that nucleosides are intrinsically polar, general C18 columns are not always sufficient for separation of certain nucleosides, such as pyrimidines and their derivatives. While addition of $10 \mathrm{mM}$ sodium or ammonium acetate into the aqueous buffer at a $\mathrm{pH} \sim 4.5$ enhances the separation and resolution of individual nucleosides, the chromatography parameters must be tailored to the individual needs of each study, focusing on complete resolution of the analytes of interest. This concern has spurred the application of hydrophilic interaction liquid chromatography (HILIC), in order to increase retention and resolution of nucleosides carrying polar modifications [91,141,142]. Though LC with UV-Visible detection has been an invaluable tool for analysis of tRNA modifications in years past, it is limited by sensitivity and the requirement of commercially available standards (Table 3) to validate retention times. The recent discovery of several previously unidentified nucleoside modifications has exacerbated this challenge, as manufacturers 
have not yet caught up to the field in terms of providing a complete set of hyper-modified nucleosides on the market, including many nucleosides which are dually modified.

\subsubsection{Advances in Liquid Chromatography-Mass Spectrometry Methods for Detection of} tRNA Modifications

Analysis of modified tRNA nucleosides using LC techniques coupled to mass spectrometry (LC-MS) has become increasingly popular. The recent discovery of novel modifications previously overlooked by methods described above is attributed to the recent developments in both instrumentation and technology for data analysis. In addition to detecting and quantifying an ion of a precise molecular weight with great sensitivity, fragmentation of the ion of interest, using tandem LC-MS/MS simultaneous enables structural validation and identification of multiple analytes (Table 3). For relative quantification, modified nucleosides occurring in great abundance such as pseudouridine, dihydrouridine, and inosine are often used as internal standards to normalize modification levels between samples. However, it is important to take into consideration the tRNA isolation method and degree of purification, as some of these modifications occur in additional RNA species and thus small degrees of contaminants could widely skew results. Of the tRNA nucleosides listed in Table 3, pseudouridine, dihydrouridine, $\mathrm{m}^{2} \mathrm{~A}$ and $\mathrm{m}^{6} \mathrm{~A}$ are all found in bacterial rRNA [143-148]. This leaves inosine as an attractive internal standard candidate. Although it has only been observed in bacterial tRNA, it is important to note that both inosine and $\mathrm{m}^{6} \mathrm{~A}$ also occur in eukaryotic mRNA $[149,150]$.

Table 3. Molecular masses of tRNA modifications dependent on sulfur metabolism and standards.

\begin{tabular}{|c|c|c|c|c|c|}
\hline \multicolumn{6}{|c|}{ S-Dependent Modifications } \\
\hline Modification & Name & $\begin{array}{l}\text { Monoisotopic } \\
\text { Mass (amu) }\end{array}$ & $\begin{array}{c}\text { Observed } \\
\text { Molecular Ion } \\
(\mathrm{m} / \mathrm{z+})\end{array}$ & $\begin{array}{c}\text { Major } \\
\text { Fragment } \\
(m / z+)\end{array}$ & Standard ** \\
\hline $\mathrm{s}^{2} \mathrm{C}$ & 2-thiocytidine & 259.063 & 260.071 & 128.028 & 1 \\
\hline $\mathrm{s}^{2} \mathrm{U}$ & 2-thiouridine & 260.047 & 261.055 & $129.009 *$ & 1 \\
\hline $\mathrm{s}^{4} \mathrm{U}$ & 4-thiouridine & 260.047 & 261.055 & 129.009 * & 2 \\
\hline $\mathrm{s}^{2} \mathrm{Um}$ & 2-thio-2'-O-methyluridine & 274.062 & 275.067 & $129.008^{*}$ & \\
\hline $\mathrm{m}^{5} \mathrm{~s}^{2} \mathrm{U} / \mathrm{s}^{2} \mathrm{~T}$ & 5-methyl-2-thiouridine/2-thioribothymidine & 274.062 & 275.062 & 143.019 & 1,2 \\
\hline $\mathrm{m}^{2} \mathrm{~A}^{+}$ & $N^{2}$-methyladenosine ${ }^{+}$ & 281.112 & 282.114 & 150.071 & \\
\hline $\mathrm{nm}^{5} \mathrm{~s}^{2} \mathrm{U}$ & 5-methylaminomethyl-2-thiouridine & 289.073 & 290.081 & 158.038 & \\
\hline $\mathrm{mnm}^{5} \mathrm{~s}^{2} \mathrm{U}$ & 5-methylaminomethyl-2-thiouridine & 303.089 & 304.097 & $172.057 *$ & \\
\hline $\mathrm{se}^{2} \mathrm{U}$ & 2-selenouridine & 305.992 & 306.999 & 174.956 & \\
\hline $\mathrm{ms}^{2} \mathrm{~m}^{6} \mathrm{~A}$ & 2-methylthio- $N^{6}$-methyladenosine & 327.100 & 328.108 & 196.065 & \\
\hline $\mathrm{cmnm}^{5} \mathrm{~s}^{2} \mathrm{U}$ & 5-carboxymethylaminomethyl-2-thiouridine & 347.079 & 348.082 & $216.047^{*}$ & \\
\hline $\mathrm{mnm}^{5} \mathrm{se}^{2} \mathrm{U}$ & 5-methylaminomethyl-2-selenouridine & 349.034 & 350.034 & 217.991 & \\
\hline inm $^{5} \mathrm{~s}^{2} \mathrm{U}$ & 5-(isopentenylaminomethyl)-2-thiouridine & 357.136 & 358.144 & 226.101 & \\
\hline $\mathrm{ms}^{2} \mathrm{i}^{6} \mathrm{~A}$ & 2-methylthio- $N^{6}$-isopentenyladenosine & 381.147 & 382.155 & $250.108 *$ & 1 \\
\hline $\mathrm{cmnm}^{5} \mathrm{se}^{2} \mathrm{U}$ & 5-carboxymethylaminomethyl-2-selenouridine & 393.024 & 394.032 & 261.989 & \\
\hline $\mathrm{ct}^{6} \mathrm{~A}$ & cyclic $N^{6}$-threonylcarbamoyladenosine & 394.124 & 395.128 & $263.089 *$ & \\
\hline $\operatorname{ges}^{2} U$ & 2-geranylthiouridine & 396.172 & 397.180 & 265.137 & \\
\hline $\mathrm{ms}^{2} \mathrm{io}^{6} \mathrm{~A}$ & 2-methylthio- $N^{6}$-(cis-hydroxyisopentenyl) adenosine & 397.142 & 398.150 & 266.107 & \\
\hline Q & queuosine & 409.160 & 410.168 & 278.125 & \\
\hline $\mathrm{nm}^{5} \operatorname{ges}^{2} \mathrm{U}$ & 5-methylaminomethyl-2-geranylthiouridine & 425.198 & 426.206 & 294.163 & \\
\hline $\mathrm{mnm}^{5}$ ges $^{2} \mathrm{U}$ & 5-methylaminomethyl-2-geranylthiouridine & 439.214 & 440.222 & 308.179 & \\
\hline $\mathrm{ms}^{2} \mathrm{ct}^{6} \mathrm{~A}$ & 2-methylthio-cyclic- $N^{6}$-threonyl carbamoyladenosine & 440.111 & 441.119 & 309.076 & \\
\hline $\mathrm{ms}^{2} \mathrm{t}^{6} \mathrm{~A}$ & 2-methylthio- $N^{6}$-threonyl carbamoyladenosine & 458.112 & 459.130 & $182.049 *$ & \\
\hline $\mathrm{ms}^{2} \mathrm{hn}^{6} \mathrm{~A}$ & 2-methylthio- $N^{6}$-hydroxynorvalylcarbamoyladenosine & 472.138 & 473.146 & 341.103 & \\
\hline $\mathrm{cmnm}^{5}$ ges $^{2} \mathrm{U}$ & 5-carboxymethylaminomethyl-2-geranylthiouridine & 483.204 & 484.212 & 352.169 & \\
\hline
\end{tabular}


Table 3. Cont.

\begin{tabular}{|c|c|c|c|c|c|}
\hline \multicolumn{6}{|c|}{ Precursor and Related Modifications } \\
\hline Modification & Name & $\begin{array}{l}\text { Monoisotopic } \\
\text { Mass (amu) }\end{array}$ & $\begin{array}{c}\text { Observed } \\
\text { Molecular Ion } \\
(\mathrm{m} / \mathrm{z+})\end{array}$ & $\begin{array}{c}\text { Major } \\
\text { Fragment } \\
(m / z+)\end{array}$ & Standard ** \\
\hline $\mathrm{cmnm}^{5} \mathrm{Um}$ & 5-carboxymethylaminomethyl-2'-O-methyluridine & 345.117 & 346.117 & $200.058^{*}$ & \\
\hline $\mathrm{m}^{6} \mathrm{~A}$ & $N^{6}$-methyladenosine ${ }^{t, \ddagger}$ & 281.112 & 282.114 & $150.071 *$ & 1 \\
\hline $\mathrm{mnm}^{5} \mathrm{U}$ & 5-methylaminomethyluridine & 287.112 & 288.120 & $156.074 *$ & \\
\hline$i^{6} \mathrm{~A}$ & $N^{6}$-isopentenyladenosine & 335.159 & 336.167 & $204.119 *$ & 1 \\
\hline $\operatorname{inm}^{5} \mathrm{U}$ & 5-(isopentenylaminomethyl) uridine & 341.159 & 342.167 & 210.135 & \\
\hline io ${ }^{6} \mathrm{~A}$ & $N^{6}$-(cis-hydroxyisopentenyl) adenosine & 351.154 & 352.156 & 220.115 * & \\
\hline inm $^{5} \mathrm{Um}$ & 5-(isopentenylaminomethyl)-2'-O-methyluridine & 355.174 & 356.182 & 224.139 & \\
\hline$t^{6} \mathrm{~A}$ & $N^{6}$-threonylcarbamoyladenosine & 412.134 & 413.142 & $136.062 *$ & 3 \\
\hline $\mathrm{oQ}$ & epoxyqueuosine & 425.155 & 426.163 & 294.120 & \\
\hline$h n^{6} \mathrm{~A}$ & $N^{6}$-hydroxynorvalylcarbamoyl adenosine & 426.150 & 427.158 & 295.115 & \\
\hline \multicolumn{6}{|c|}{ Common Internal Standards } \\
\hline Modification & Name & $\begin{array}{c}\text { Monoisotopic } \\
\text { Mass (amu) }\end{array}$ & $\begin{array}{c}\text { Observed } \\
\text { Molecular Ion } \\
(\mathrm{m} / \mathrm{z+})\end{array}$ & $\begin{array}{c}\text { Major } \\
\text { Fragment } \\
(m / z+)\end{array}$ & Standard ** \\
\hline I & Inosine $\ddagger$ & 268.081 & 269.088 & $137.047 *$ & 2 \\
\hline$\Psi$ & Pseudouridine $^{\dagger}$ & 244.070 & 245.078 & $209.052 *$ & 2 \\
\hline $\mathrm{D}$ & Dihydrouridine $^{\dagger}$ & 246.085 & 247.092 & $115.050 *$ & 4,5 \\
\hline \multicolumn{6}{|c|}{$\begin{array}{l}\text { * major fragment masses have been experimentally validated [151]; }{ }^{* *} \text { commercially available standards: } \\
\text { 1-Carbosynth Ltd., Berkshire, United Kingdom, 2-Sigma-Aldrich, St Louis, MO, USA, 3-BioLog Life Science } \\
\text { Institute, Bremen, Germany, 4-Advanced Technology \& Industrial Co., Ltd., Hong Kong, China, 5-Dalton Pharma } \\
\text { Services, Toronto, Canada; }{ }^{\dagger} \text { Also found in bacterial ribosomal RNA; }{ }^{\ddagger} \text { Has not been found in bacterial messenger } \\
\text { RNA, but occurs in eukaryotic mRNA. }\end{array}$} \\
\hline
\end{tabular}

Typically, identification of new modified nucleosides is enabled with the use of tandem triple quadrupole (QQQ) or high mass accuracy mass spectrometers (LTQ-Orbitrap) with an electrospray ionization (ESI) source in positive-ion mode, as both aqueous (water) and organic (acetonitrile or methanol) solvents have $0.1 \%$ formic acid added to facilitate ionization. Tandem MS/MS is used to fragment the ion, and neutral loss analysis provides a way to identify bases originating from nucleosides, as they lose an uncharged mass associated with a ribose ring (Table 3). Although quadruple time of flight (Q-TOF) and Orbitrap high mass accuracy mass spectrometers are sufficient for relative quantification, the use of a tandem QQQ LC-MS/MS with ESI is advised for absolute nucleoside quantification, as its capacity for sensitivity is superior to that of other instrumentation. Supplementation of an additional and complementary Q-TOF MS/MS method and/or various nuclear magnetic resonance (NMR) spectroscopy techniques can also aid in structural assignment $[116,152,153]$.

LC-MS/MS has also demonstrated its utility in tRNA analysis through methods that determine the exact position at which a modified nucleoside occurs within one or more tRNA species. One strategy is to analyze tRNA isolated through affinity purification and subsequently digested into nucleosides. Alternatively, total tRNA can be digested with one or more sequence specific RNase(s) to yield oligonucleotides of predicted sizes. These oligonucleotides can then be applied to a C18 column coupled to a QQQ MS with ESI in negative mode for LC-MS/MS detection. Online resources, such as the Mongo Oligo Mass Calculator, facilitate easy predictions of expected masses based on instrument ionization settings and RNase(s) used for digestion [119,154,155].

In 2010, Chan et al. made use of the aforementioned LC-MS techniques to develop a systems-level approach for studying dynamic changes in tRNA modification levels in Saccharomyces cerevisiae cells exposed to various stresses [156]. This and subsequent studies resulted in the discovery that in stress conditions, altered tRNA modification levels directly impact synthesis of codon-biased stress response proteins $[118,152,157,158]$. For this technique, tRNA isolated from cells exposed to the stress condition of interest was isolated, purified, digested into nucleosides and quantified with LC-MS/MS. Upon data normalization and multivariate statistical analysis, a map of significant changes within tRNA 
modifications was generated. Recent reports have provided a comprehensive review of the methods involved in the systems-level approach for tRNA modification analysis [116,159]. Altogether, emerging advances in LC-MS techniques for RNA modification analysis have revealed underappreciated roles for tRNA modifications in cellular metabolism. These findings suggest that we have only begun to scratch the surface of their biological relevance, thus providing a direction for future research and simultaneously demonstrating the value of investing in tools to facilitate analysis of biological samples.

\section{Biosynthesis of Thionucleosides in Bacterial tRNA}

Methods for detection and quantification of tRNA from biological samples such as the ones described in this review have been critical tools for the analysis of thio-modifications. Investigation of pathways involved in the synthesis of thio-modifications of tRNA as well as discovery of new intermediates in these pathways were afforded through a combination of genomics, genetic, and biochemical approaches validated with spectroscopic and analytical methods for structural identification and quantification of these reaction products. Here, we summarize the current knowledge on the biological synthesis of major thionucleosides in bacteria.

\subsection{4-thiouridine $\left(s^{4} U\right)$}

Sulfur-modification on the uridine at position 8 of tRNA has been known for over half a century [160]. It serves as a photo-sensor in bacteria and archaea for cells mediating the stringent response under environmental UV stress. Due to its unique $\lambda_{\max }$ at $330 \mathrm{~nm}, \mathrm{~s}^{4} \mathrm{U}$ has also been explored as a photoreactive ribonucleoside analog in RNA synthetic studies [161]. There are currently three synthetic pathways for the biosynthesis of $s^{4} U$ in Bacteria and Archaea. The first pathway reported is the one utilized by the model Gram-negative bacterium, E. coli, and it has provided extensive mechanistic details involving nucleoside thiolation and general persulfide transfer reactions. The synthesis of this modification involves the sulfur activating enzyme IscS and the dually functional thiouridylase ThiI (Table 1) [11,12,62,64,66,162]. Earlier studies in Salmonella enterica have shown that both enzymes also participate in the synthesis of thiamine. In both pathways, IscS uses pyridoxal $5^{\prime}$-phosphate (PLP) to activate the amino acid cysteine, enabling the formation of an enzyme persulfide intermediate, and the release of alanine. The subsequent step in this reaction mechanism is the transfer of persulfide sulfur to an acceptor molecule. In the biosynthesis of $s^{4} U$ and thiamine, the Cys456 residue of ThiI, residing within the rhodanese domain, serves as the sulfur acceptor site [70]. Interestingly, in thiamine formation, this C-terminal rhodanese domain is both necessary and sufficient for the function of Thil in this pathway [66].

Specific to ${ }^{4} U$ synthesis, the activity of ThiI also depends on other structural and functional domains located towards the N-terminus. While the C-terminal rhodanese sulfur transfer domain appears to be missing in certain ThiI sequences, structural and sequence analyses reveal the presence of three additional majorly conserved domains [67,69] comprehending a large thiouridylase domain. The THUMP (named after thiouridine synthases, RNA methylases and pseudouridine synthases) domain is involved in recognition of the $3^{\prime}$-CCA end of tRNA and positioning the uridine in the correct orientation for catalysis [67]. The N-terminal Ferredoxin-like domain (NFLD) is also involved in the binding of tRNA [69], while the C-terminal PPase domain contains an adenylation-specific PP-loop motif (SGGFDS) belonging to the $\mathrm{PP}_{\mathrm{i}}$ synthetase superfamily [65]. This signature motif is also found in other tRNA adenylating enzymes, including the 2-thiocytidine and 2-thiouridine biosynthetic enzymes, TtcA and MnmA, and uses ATP to activate the appropriate uridine carbonyl groups in substrates [94,163]. Thus, the adenylation step serves to introduce a good leaving group for the following nucleophilic attack of sulfur intermediate species (Figure 3).

The proposed mechanism first evokes the ThiI adenylation reaction of the C4 of tRNA U8, followed by the sulfur transfer reaction by the persulfurated form of ThiI with the concomitant release of AMP. Two reaction paths have been proposed for the final sulfur transfer step [162]. The mechanism described in Figure 3 involves the direct nucleophilic attack of the persulfide sulfur onto the adenylated 
intermediate, which is then resolved by another residue Cys344, thereby regenerating the enzyme for subsequent turnover. The mechanism of $\mathrm{s}^{4} \mathrm{U}$ formation can also be explained by an alternative proposal in which Cys344 acts as a nucleophile by attacking the bridging sulfur of Cys456 leading to local release of sulfide that can directly react with the tRNA intermediate [62,162]. In both schemes, the completion of the catalytic cycle is marked by formation of a disulfide bond between the Cys344 and Cys456. While these reactions can complete one turnover under non-reducing conditions, reduction of the disulfide bond between the catalytic and resolving cysteine residues is necessary for the next cycle. Multiple turnover reactions can only be achieved in vitro in the presence of reductants such as dithiothreitol (DTT), however, the identity of the physiological reductant enabling regeneration of Thi at the end of each turnover remains to be identified. Additionally, ThiI conserved residues Asp189 and Lys321 were found to be critical for Thil's enzymatic adenylation activity and consequently overall function of ThiI in $\mathrm{s}^{4} \mathrm{U}$ formation [163]. Although the aspartic acid residue lying within the PP-loop in $\mathrm{PP}_{\mathrm{i}}$ synthetases has long been established as for $\mathrm{Mg}^{+}$coordination for ATP binding and hydrolysis [164], the exact roles of the Asp189 and Lys321 residues of ThiI in ATP binding and hydrolysis or the initial deprotonation of N5 of U8 (Step 1, Figure 3), need to be further validated.

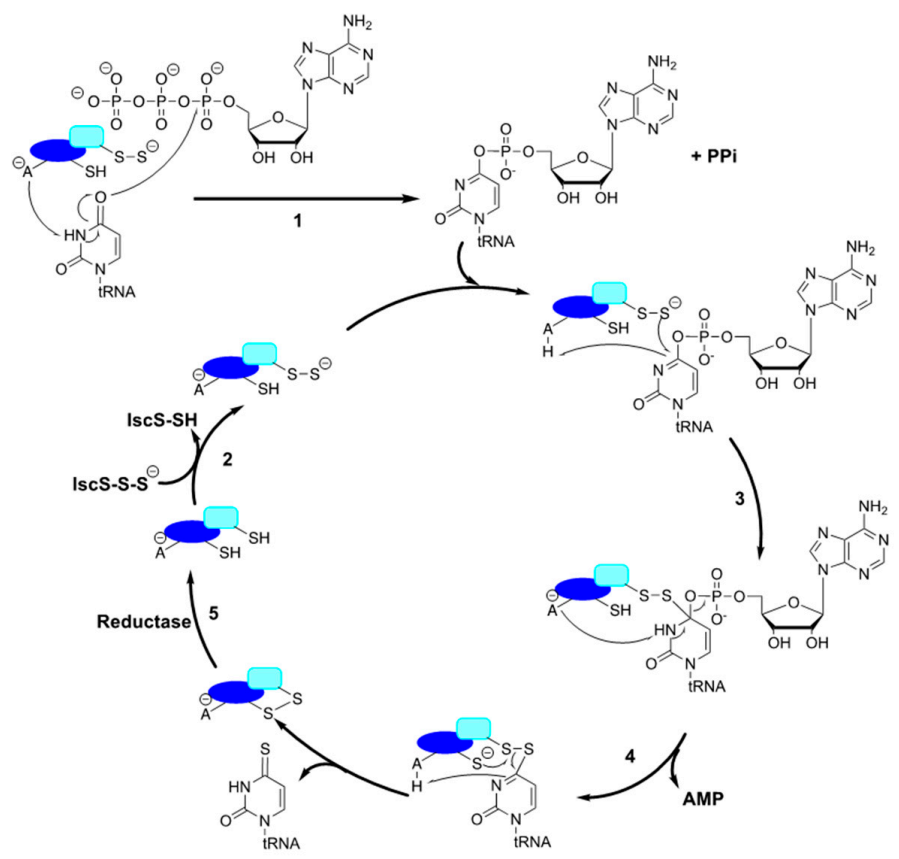

Figure 3. Proposed mechanism for thiolation of tRNA U8 by E. coli IscS and ThiI (adapted from [64,162]). The ThiI thiouridylase domain (dark blue) catalyzes the ATP-dependent adenylation of C4 of uridine and release of pyrophosphate (PPi) (1). IscS promotes persulfide sulfur transfer to Cys456 of ThiI's rhodanese-like domain (light blue) (2). In one of the proposed mechanisms, the persulfide sulfur then conducts a nucleophilic attack onto the activated C4 of U8 tRNA (3), which leads to release of the leaving group AMP (4). The reaction is then resolved through formation of a disulfide bond between Cys456 and Cys344 and release of the product s ${ }^{4} U$ tRNA (5). Regeneration of the enzyme for subsequent catalytic cycles requires the involvement of a yet unidentified reductase (5). An alternative proposal for the formation of $\mathrm{s}^{4} \mathrm{U}$ involves the local formation of sulfide at the enzyme active site which then directly attacks the adenylated intermediate (not shown). In both models, the reaction cycle is marked by the release of AMP and the $s^{4} \mathrm{U}$ tRNA product along with the formation of a disulfide bond between Cys344 and Cys456.

The pathway for $\mathrm{s}^{4} \mathrm{U}$ in Gram-positive bacteria is distinct from the one described in E. coli and S. enterica. In fact, the majority of Gram-positive bacteria don't contain IscS and encode a truncated ThiI protein lacking the rhodanese domain. The Bacillus subtilis ThiI appears to be a dedicated protein in 
$\mathrm{s}^{4} \mathrm{U}$ biosynthesis and it is not required for thiamine generation [165]. Interestingly, B. subtilis contains four cysteine desulfurases and evidence thus far has demonstrated that each pairs with a dedicated sulfur transferase for specific thiocofactor generation $[68,72,166]$. Formation of $\mathrm{s}^{4} \mathrm{U}$, in particular, is accomplished by the cysteine desulfurase NifZ, the coding sequence of which is found immediately upstream of thil. Though the truncated ThiI protein lacks the rhodanese (Rhd) domain, it contains the NFLD, THUMP and PPase domains involved in adenylation and thiolation of U8 [68]. Despite the missing rhodanese domain, B. subtilis ThiI is capable of receiving the persulfide sulfur from NifZ, and both proteins together are sufficient in completing $s^{4} U$ synthesis. The B. subtilis ThiI contains four cysteine residues, including Cys344 at a position equivalent to E. coli Thil Cys344. However, the involvement of B. subtilis ThiI Cys344 and/or an alternate Cys residue serving as the sulfur acceptor site awaits experimental investigation. Nevertheless, based on the proposed mechanism of $E$. coli ThiI involving two cysteine residues, it is possible that more than one Cys residue within B. subtilis ThiI uridylase domain is involved in thiolation. Alternatively, due to the presence of a dedicated cysteine desulfurase, it is also reasonable to consider that in addition to promote persulfide transfer, NifZ may also involved in completing Thil's catalytic cycle by providing a resolving cysteine at the end of the catalytic cycle.

A third pathway for $\mathrm{s}^{4} \mathrm{U} 8 \mathrm{tRNA}$ formation was recently reported for the archaeal species Methanococcus maripaludis [167]. Like Gram-positive bacteria, most archaeal species do not contain a master/housekeeping IscS-like cysteine desulfurase and ThiI sequences lack the Rhd domain. Mutagenesis studies showed that the three conserved cysteine residues are essential for the function of ThiI, and Ala substitution of any of these residues eliminates the ability of this protein to serve as a sulfur acceptor [168]. Recent spectroscopic studies demonstrated that M. maripaludis Thil is capable of coordinating a [3Fe-4S] cluster which has been assigned as an important element for the functionality of this protein, however the exact role of this cluster as structural, catalytic or a sacrificial sulfur source has not been determined [167].

\subsection{2-thiouridine $\left(s^{2} U\right)$}

The 2-thiouridine modification is located on the third (wobble) position of the anticodon in

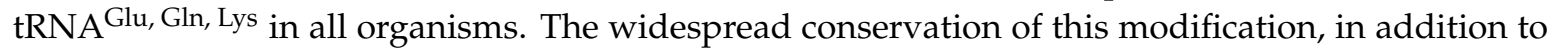
the metabolic defects associated with its absence in various species demonstrates the utility of this modification in metabolism. Eukaryotic organisms such as Saccharomyces cerevisiae contain two distinct machineries for $\mathrm{s}^{2} \mathrm{U}$ biosynthesis in the cytoplasm vs. the mitochondria. Notable differences in the machineries are the usage of Fe-S proteins and sulfur transfer via protein-thiocarboxylate formation in the cytoplasmic pathway $[135,167,169,170]$. The mitochondrial pathway, however, resembles that used in bacteria, as it is [Fe-S] cluster independent, and utilizes persulfide sulfur transfer rather than thiocarboxylation $[171,172]$.

\subsubsection{E. coli 2-thiouridine Biosynthesis: Assembly Line of Sulfur Transfer}

The biosynthesis of $s^{2} U$ has been extensively studied in $E$. coli, which involves participation of six different enzymes. In both E. coli and S. enterica, the cysteine desulfurase IscS also serves as the sulfur source by transferring its persulfide sulfur to TusA [37,52]. The small sulfurtransferase TusA then interacts with and transfers sulfur to TusD, when in a heterohexameric $\left(\alpha_{2} \beta_{2} \gamma_{2}\right)$ complex with additional components TusB and TusC. TusE serves as an intermediate between the TusBCD complex and the thiouridylase, MnmA [37,70]. The latter has dual functions analogous to those aforementioned for ThiI: adenylation and thiolation. TusE can form a ternary complex with MnmA and tRNA and it was initially unclear whether MnmA could thiolate the tRNA following adenylation, or if TusE being in the ternary complex was necessary for sulfur insertion. However, structural and functional studies have confirmed that persulfurated MnmA is both capable and sufficient for adenylation and thiolation of U34 tRNA [71,173]. 
In Gram-positive bacteria, the biosynthesis of $s^{2} U$ utilizes an abridged pathway. Genomic analysis of several Gram-positive species pointed to the absence of sequences encoding Tus proteins. Interestingly, in B. subtilis and in several other Gram-positive species missing tus genes, an IscS-like cysteine desulfurase gene $(\mathrm{yrvO})$ is located in the same genomic region, and commonly directly upstream, of $m n m A$. Experimental characterization of B. subtilis YrvO and MnmA both in vivo and in vitro demonstrated that these two proteins are the sole requirements for $s^{2} U$ formation in this bacterium [72]. It is worth noting that the B. subtilis genome encodes a rhodanese protein (YrkF) with homology to TusA which is a competent sulfur acceptor of $\mathrm{YrvO}$, but inactivation of yrkF leads to no changes in $s^{2} U$ levels $[72,174]$. These findings highlight an important difference in thiocofactor biosynthesis between Gram-positive and negative bacteria, in that the presence of a devoted cysteine desulfurase in B. subtilis eliminates the need of the intricate Tus sulfur transfer system through direct interaction with MnmA. The conservation of the yrvO-mnmA gene region and lack thereof the Tus system suggests that the abbreviated $\mathrm{s}^{2} \mathrm{U}$ biosynthetic pathway used in $B$. subtilis is common to Gram-positive bacteria. In Gram-negative E. coli, which uses the housekeeping IscS for sulfur mobilization to all thiocofactors $[11,53,54]$, the Tus proteins also participate in additional metabolic pathways [71,175-177]. The multi-functionality of these and other enzymes in thiocofactor pathways has been attributed to the utilization of one major cysteine desulfurase (i.e., IscS) for all thiocofactors in Gram-negative bacteria and simultaneously demonstrates the resulting complexity of sulfur trafficking in these organisms $[178,179]$. The recruitment of small sulfur acceptor proteins or sulfurtransferase domains within individual pathways can be seen as a mechanistic strategy for controlling sulfur flux in organisms such as E. coli that utilize a master sulfur donor. While in other systems, such as the Gram-positive B. subtilis, the biosynthetic apparatus is much simpler.

\subsection{2. tRNA Binding and Adenylation by MnmA}

Similar to the ThiI reaction (Figure 3), the thiouridylase MnmA has two functions in addition to acting as a sulfur acceptor protein: adenylation of the tRNA substrate, followed by thiolation at the C2 position of U34. The exact sequence of events for substrate binding and activity is still unclear, however Numata et al. provided detailed insight into this process via three structures of E. coli MnmA in complex with $\mathrm{tRNA}^{\mathrm{Glu}}$ which illustrates the initial binding, the pre-reaction, and the adenylated intermediate states [173]. The structures of the MnmA-tRNA complex showed that in its initial tRNA binding state, MnmA displays an open conformation, with the variable segment coiled back in an $\alpha$ helix, whereas in the pre-reaction and adenylated intermediate states, it undergoes a subtle rearrangement, in which the variable segment is extended, adopting a "closed conformation" to shield U34 from the solvent and position it closer to the catalytic residues (Figure 4) [173]. In both E. coli and B. subtilis, sulfur transfer to MnmA was only observed in the presence of ATP, suggesting that ATP-bound MnmA is the catalytically competent form of the enzyme [72,173]. The mechanisms by which ATP binding elicits activation of MnmA as a sulfur acceptor are not known. However, it seems mechanistically advantageous for the enzyme to require ATP prior to accepting a persulfide sulfur, to ensure the availability of all necessary reaction components prior to binding tRNA and closing its active site. It is tempting to speculate that ATP binding induces a conformational change in the enzyme to render its active state. However, the only crystal structure in which ATP was present was that of the adenylated intermediate state, meaning that the closed conformation in the E. coli MnmA pre-reaction state was not induced by ATP. Interestingly, the ATP dependence for sulfurtransferase activity is not observed in Thil from either organism $[68,162,180]$. Considering that $E$. coli ThiI contains a rhodanese sulfurtransferase domain, and that ATP is not necessary for its' additional function in thiamine biosynthesis, it seems logical that its sulfurtransferase activity is independent of ATP binding [68]. Alternatively, B. subtilis ThiI lacks the rhodanese domain and does not participate in thiamine formation, yet its competency in the sulfur transfer event is independent of ATP. Collectively, this suggests that the requirement for ATP binding to MnmA for sulfur transfer is a unique feature of this enzyme, rather than a characteristic common to all thiouridylases. 


\subsubsection{Proposed Order for tRNA U34 Modification}

The U34 modifications at the C2 and C5 positions have been suggested to occur independent of one another. Indeed, neither modification is strictly required to be present in order for the other to be synthesized, as strains deficient in the genes coding for the $C 5$ modifying enzymes accumulate $s^{2} \mathrm{U}$ and vice versa $[181,182]$. However, investigation of B. subtilis MnmA's substrate preferences via in vitro $\mathrm{s}^{2} \mathrm{U}$ reconstitution experiments using native tRNA from an E. coli $\triangle m n m A$ strain, and enriched for mnm ${ }^{5} \mathrm{U} 34 \mathrm{tRNA}$, demonstrated a clear preference for modification of hypomodified U34 [72]. Evaluation of the MnmA-tRNA complex structure in the pre-reaction state (i.e., closed conformation; Figure 4, right) shows that the Phe154 and Asp99 are positioned $4 \AA$ away from C5 of the U34 and that C5 provides a van der Waals interaction with the Phe154 aromatic ring. Furthermore, MnmA's tRNA substrates also contain A37 modifications, and when $t^{6} \mathrm{~A} 37$ was superimposed on the structure, it was proposed that it might provide contacts to stabilize the MnmA-tRNA interaction, suggesting that A37 modification(s) may precede U34 thiolation [173]. Altogether, the substrate preference of B. subtilis MnmA for hypomodified U34 tRNA, along with the steric hindrance potentially imposed by the $\mathrm{mnm}^{5}$ group, which would be compounded in an A37 modified tRNA anticodon suggest that a sequential order for U34 modification exists, with thiolation preceding C 5 modification. In the past decade, significant progress has been made towards understanding the intricacies of $s^{2} U$ biosynthesis. However, differences in experimental design of studied systems often explored through in vitro reactions using hypomodified synthetic transcripts make it difficult to draw general conclusions about the order of modifications. Therefore, future work must capitalize on the powerful analytical tool provided by evaluation of both synthetic and biological tRNA samples using newly developed sensitive and accurate techniques for detection of modifications and associated intermediates present at low abundance.
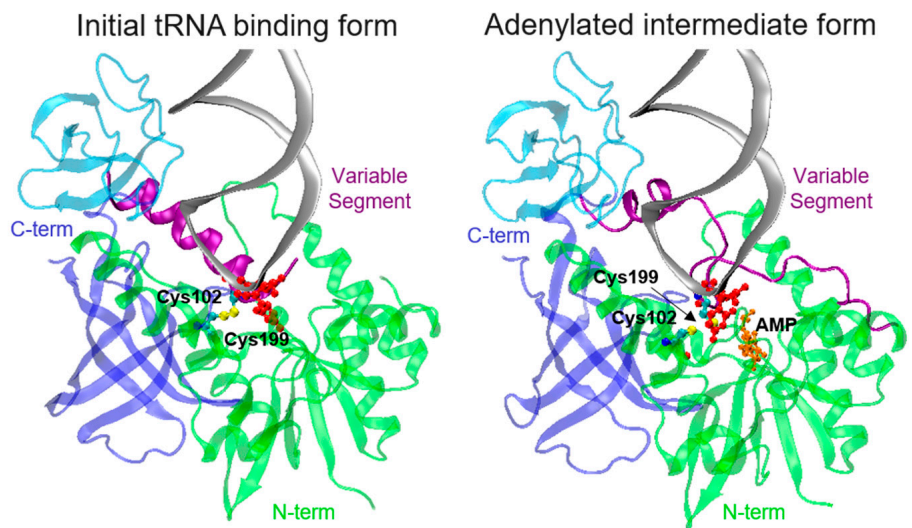

Figure 4. E. coli $\mathrm{MnmA}$ in complex with $\mathrm{tRNA}^{\mathrm{Glu}}$. The structure of the E. coli 2-thiouridine biosynthetic enzyme MnmA is shown in complex with tRNA Glu (gray) in the initial tRNA binding form (2DER, left) and the tRNA adenylated intermediate form (2DEU, right). E. coli MnmA is colored by domain; the $\mathrm{N}$-terminal catalytic domain (residues 4-215) is shown in green, while the central domain (residues 216-277), variable segment (residues 187-215) and the C-terminal domain (residues 278-368) are shown in cyan, purple and blue, respectively. U34 is shown in red and AMP is displayed in in orange. The sulfur atoms of the MnmA catalytic Cys residues, 102 and 199, are shown in yellow. C-term: C-terminal and N-term: N-terminal.

The $\mathrm{s}^{2} \mathrm{U} 34$ modification at the $\mathrm{C} 2$ position can be further modified either by addition of a geranyl group, or the sulfur can be substituted for selenium, but both modifications require thiolation of U34 as a precursor. Interestingly, in E. coli both modification reactions are catalyzed by the $\mathrm{MnmH}$ (SelU/SufY/YbbB) rhodanese domain containing protein [81,183]. It is not surprising that a rhodanese protein can substitute sulfur for selenium, as both atoms are similar in structure and physicochemical properties. Yet, the geranyl modification is entirely different (Figure 2), as it is a large hydrophobic 
moiety and could influence the structure and function of the tRNA, thereby impacting translation [83,184]. In fact, the geranyl group lends specificity by preferentially binding codons ending in G [29]. It is estimated that approximately $3 \%-7 \%$ of $\mathrm{s}^{2} \mathrm{U} 34$ tRNAs are geranylated at a given time, and this can vary, as selenation rather than geranylation is observed at selenium concentrations above $10 \mathrm{nM}$. It was initially proposed that geranylation is an alternative to selenation when Se is limiting [29]. However, co-purification of MnmH with an enriched geranyl-modified tRNA population bound to it $[80,81]$ suggests that geranylated tRNA may in fact serve as an intermediate for selenation in vivo. This could also explain the significantly low levels of ges ${ }^{2} U$ under normal growth conditions. Although in vitro selenation reactions have demonstrated that geranylation is not required for synthesis of $\operatorname{se}^{2} \mathrm{U}$ [80], it seems likely that the sulfur atom in its thioether form with a bulky geranyl group attached would be a better leaving group than sulfur in its thioketone form. Thus, perhaps geranylation of $s^{2} U$ enhances the turnover rate of MnmH's selenation activity. Kinetic characterization of MnmH's dual activities and substrate preferences alone or in competition assays would certainly enable clarification of the sequence of reactions performed by this enzyme. The physiological relevance of the $\mathrm{se}^{2} \mathrm{U}$ modification stems from the narrow range in which Se is beneficial $(0.1-1 \mu \mathrm{M})$. Similar to sulfide, free selenide is highly reactive, and levels above $10 \mu \mathrm{M}$ are toxic to many bacteria, providing a rationale for detoxification mechanisms [185]. Although it is well known that Se incorporation into certain enzymes in the form of selenocysteine (Sec) is important for high enzymatic activity, the function of $\mathrm{se}^{2} \mathrm{U}$ is poorly understood. Considering the similar structural and physicochemical properties of sulfur and selenium, it seems redundant for the cell to convert one modification to the other if their functions are the same. An alternative explanation for $\mathrm{se}^{2} \mathrm{U}$ formation would be as a way of shuttling Se into a non-toxic form, by converting Sec pools to $\mathrm{se}^{2} \mathrm{U}$, thus having a smaller impact on intracellular redox and preventing its interference in normal sulfur metabolism, while maintaining the initial function of the C2 modification of tRNA U34.

Recent studies investigating the mechanism of catalysis for MnmH's two distinct activities have shed light on the contributions from this protein which dictate formation of each modification. Though the conserved Cys97 in the rhodanese domain is required for selenation of U34, this same residue is not necessary for geranylation [80]. There is however, a 36 amino acid insertion sequence in the rhodanese domain of $\mathrm{MnmH}$ orthologues that when altered, increases geranylation. This insertion is not found in single domain rhodanese proteins and analysis of many different $\mathrm{MnmH}$ variants altered within this region suggested that the size of residues, rather than its chemical properties, were important for enhanced geranylation [81,152]. Another interpretation is that mutation of residues within the rhodanese domain prohibit further modification from ges ${ }^{2} U$ to selenation, and consequently the higher extent of geranylation represents intermediate build-up. An intact Walker motif in the MnmH P-loop domain is proposed to be the binding site for the substrate geranylpyrophosphate (GePP), while the domain itself is necessary for tRNA binding and thus for both activities. Altogether, the two distinct activities of $\mathrm{MnmH}$ are apparent and involve either distinct or potentially sequential chemistries, and further exploration will be required to deconvolute this biosynthetic pathway and place it in a cellular context. In addition to E. coli, other species containing MnmH and consequently carrying geranyl $\mathrm{s}^{2} \mathrm{U}$ include Enterobacter aerogenes, Psdeudomonas aeruginosa, and Salmonella typhimurium (Table 1). Not surprisingly, this modification was not detected in Vibrio fischeri, B. subtilis, or several different eukaryotic organisms lacking the $m n m H$ gene [81].

\subsection{2-thiocytosine $\left(s^{2} C\right)$}

Thiolation of cytosine at the $\mathrm{C} 2$ position $\left(\mathrm{s}^{2} \mathrm{C}\right)$ is a thio-modification that is not as well studied as other modifications described in this review. This thionucleoside has been reported in bacteria and some archaeal species, including Thermococcus sp. [186,187]. This modification is present at position 32 of only four $t R N A$ species ( $\mathrm{tRNA}_{\mathrm{ICG}}, \mathrm{tRNA}_{\mathrm{CCG}}, \mathrm{tRNA}_{\mathrm{mnm5UCU}}$, and $\mathrm{tRNA} \mathrm{GCU}_{\mathrm{G}}$ ) in E. coli and S. enterica [63]. Like other thionucleosides, sulfur from cysteine is activated through a cysteine desulfurase as the ultimate sulfur source for $\mathrm{s}^{2} \mathrm{C}$ formation. Initial work showed that the formation of 
$\mathrm{s}^{2} \mathrm{C}$ along with $\mathrm{ms}^{2} \mathrm{i}^{6} \mathrm{~A} / \mathrm{ms}^{2} \mathrm{t}^{6} \mathrm{~A}$ not only requires IscS but also depends on the activity of the [Fe-S] cluster scaffold protein IscU, indicating the role of [Fe-S] clusters in these biosynthetic pathways. Besides the requirement of [Fe-S] cluster biosynthetic genes, the biosynthesis of $\mathrm{s}^{2} \mathrm{C}$ also requires the product of the $t t c A$ gene [63]. The TtcA sequence bears a ${ }^{39}$ SGGGKDS ${ }^{45}$ PP-loop, the structural motif belonging to the ATPase superfamily which also includes the aforementioned ThiI and MnmA thiouridylases. Therefore, it was proposed that TtcA also uses an adenylation mechanism similar to that of ThiI, MnmA, TtuA, and TilS to activate the carbonyl substrate and yield a tRNA-AMP intermediate (Figure 3).

The events leading to subsequent sulfur insertion into the $\mathrm{C} 2$ position of tRNA C32 are less understood. Isolation of TtcA showed the presence of a [4Fe-4S] cluster likely coordinated by three Cys residues. Mutagenesis studies showed that Cys 122, 125, and 222 are critical for cluster accumulation and in vivo function of TtcA. Similar to the archaeal [Fe-S] cluster-containing thiouridylase ThiI, the involvement of the cluster as either the source of sulfur in a sacrificial role, or serving as an intermediate ligand for sulfur, or perhaps simply as a structural element is not clearly defined [63,94]. Notably, ATP and a reducing agent like DTT are absolutely required for in vitro $\mathrm{s}^{2} \mathrm{C}$ reconstitution.

\subsection{Modifications within Adenosine 37}

The 37 position of tRNA, neighboring the anticodon, is always a purine and throughout all three domains of life, it is commonly modified [3,50]. Several forms of this modification have been discovered (Figure 2), that serve multiple purposes and all seem to stabilize and secure the first base pair interaction between codon and anticodon of A:U/U:A, thereby preventing frameshifting [24,39]. Furthermore, A37 modifications help to structure the anticodon loop in an open conformation for proper decoding by preventing intraloop base pairing [188]. Methylthiolation at C2 of A37 always occurs in conjunction with a modification at the $N^{6}$ position with either an isopentenyl- $\left(\mathrm{i}^{6}\right)$ or threonylcarbamoyl- $\left(\mathrm{t}^{6}\right)$ group. The $N^{6}$-isopentenyladenosine $\left(i^{6} \mathrm{~A}\right)$ modification is found in all domains of life, and in bacteria it can be further modified to include a methylthio group at the $\mathrm{C} 2$ position, yielding $\mathrm{ms}^{2} \mathrm{i}^{6} \mathrm{~A}$ and in some species, the hydroxylated derivative $\mathrm{ms}^{2} \mathrm{io}^{6} \mathrm{~A}$. The bacterial enzyme MiaA is responsible for transfer of the dimethylallyl moiety from dimethylallyl pyrophosphate to $\mathrm{C} 6$ of A37 following recognition of its $\mathrm{A}_{36} \mathrm{~A}_{37} \mathrm{~A}_{38}$ sequence containing tRNA substrate $[189,190]$.

The A37 position in tRNAs which decode ANN codons is universally modified to $t^{6} \mathrm{~A}$ [191]. Flies, plants, mammals, and some $\gamma$-proteobacteria can further methylate the N6 position of A37 in a SAM-dependent reaction by the tRNA methyltransferase TrmO to produce $\mathrm{m}^{6} \mathrm{t}^{6} \mathrm{~A}[50,88,192]$. The threonyl modification is important for translational accuracy and codon recognition as its hydrophobic moiety forms a large planar structure which facilitates base stacking and strengthens binding of A:U base pairs as mentioned above $[39,191]$. Additionally, the role of this modification in AUG start codon selection provides a justification of the reason for evolutionary conservation of this modification across all organisms. Several genes are necessary for biosynthesis of this modification; in E. coli, the $t s a C, t s a D, t s a B$, and $t s a E$ are associated with formation of $t^{6} \mathrm{~A}[11,193-195]$.

In some groups of bacteria, such as E. coli and B. subtilis, as well as fungi, plants and protists, a cyclic form of $\mathrm{t}^{6} \mathrm{~A}\left(\mathrm{ct}^{6} \mathrm{~A}\right)$ has been observed, which also enhances tRNA decoding activity. Recently, X-ray crystallography, along with LC-MS analysis of native and synthetic $\mathrm{ct}^{6} \mathrm{~A}$ enabled further characterization of the nucleoside in the hydantoin isoform, rather than the previously predicted oxazolone isoform (Figure 2), with a $\lambda_{\max }$ of $269 \mathrm{~nm}$. From the structure, it is not intuitive how the twisted position of the ring against the adenine base contributes to decoding efficiency and less understood are the effects of this further modification on translation $[87,88]$.

In E. coli, formation of $\mathrm{ct}^{6} \mathrm{~A}$ from $\mathrm{t}^{6} \mathrm{~A}$ is catalyzed by threonylcarbamoyladenosine dehydratase $\mathrm{A}$ (TcdA), previously known as CsdL (B. subtilis YrvM). TcdA catalyzes an ATP-dependent dehydration reaction of $\mathrm{t}^{6} \mathrm{~A}$ [59]. The proposed reaction mechanism likely involves the activation of the carboxyl group of the $t^{6} \mathrm{~A}$ threonyl moiety through adenylation. This step then enables the nucleophilic attack of the $\mathrm{N} 6$ nitrogen of $\mathrm{t}^{6} \mathrm{~A}$ onto the activated carboxylate group, leading to formation of the 
hydantoin ring [87]. Interestingly, in E. coli the $t c d A$ gene is located adjacent, yet in the opposite direction of $\operatorname{cs} d A$ and $c s d E$ genes encoding a cysteine desulfurase and sulfur acceptor, respectively. Although this modification does not appear to involve a sulfur transfer reaction, deletion of either gene severely impairs the levels of $\mathrm{ct}^{6} \mathrm{~A}$ and thus, the involvement of the cysteine desulfurase CsdA and sulfur acceptor CsdE in $\mathrm{ct}^{6} \mathrm{~A}$ formation remains not understood [59,85]. Interestingly, B. subtilis, Trypanosoma brucei and three plant species were recently found to contain $\mathrm{ms}^{2} \mathrm{ct}^{6} \mathrm{~A}$, which was synthesized by their TcdA and MtaB enzymes. Results from investigation into $\mathrm{ms}^{2} \mathrm{ct}^{6} \mathrm{~A}$ synthesis demonstrated that cyclization of $t^{6} \mathrm{~A}$ can occur either at $\mathrm{t}^{6} \mathrm{~A}$ or $\mathrm{ms}^{2} \mathrm{t}^{6} \mathrm{~A}$, and suggested that the levels of this hypermodification can be regulated according to specific physiological conditions. Nevertheless, while no phenotypes have been identified thus far for inactivation of either $t c d A$ or $m t a B$ in B. subtilis [88], the E. coli $\Delta t c d A$ strain displays impaired growth fitness when compared to the wild-type strain [196].

Methylthiolation of $\mathrm{C} 2$ on A37 is performed by a class of enzymes called methylthioadenosine transferases (MTTases). MTTases are comprised of three different families: MiaB, and MtaB, which modify tRNA A37, and RimO, which methylthiolates an aspartic acid residue on ribosomal protein S12 (enzyme families are represented here by their names in bacteria). Though not universally conserved, $\mathrm{MiaB}$ and MtaB homologs are dispersed between all three domains of life, whereas RimO is mainly found in eubacteria and some algae and fungi. All three MTTases contain a C-terminal TRAM domain (named after TRM2 and MiaB), typically involved in substrate recognition, and 2 [4Fe-4S] clusters. The first cluster, deemed the radical SAM cluster, is ligated by three conserved cysteine residues within a CXXXCXXC motif in the central domain of the protein, and the second (auxiliary) cluster is also ligated by three conserved cysteines in the N-terminal domain [197-200].

The requirement of the MiaB MTTase in methylthiolation at the $\mathrm{C} 2$ position of $\mathrm{i}^{6} \mathrm{~A}$, producing $\mathrm{ms}^{2} \mathrm{i}^{6} \mathrm{~A}$, was first reported in E. coli and S. typhimurium, but its homologs are found in both eukaryotes and eubacteria [33]. Archaeal species with fully sequenced genomes contain only one MTTase, with homology to cyclin-dependent-like kinase 5 repressor/activator site-binding protein 1-like 1 (CDKAL1) [201], the mammalian enzyme responsible for methylthiolation of $\mathrm{ms}^{2} \mathrm{t}^{6} \mathrm{~A}$ [112]. Although the archaeal homologs have yet to be characterized experimentally, bioinformatics suggests that either archaea lack the $\mathrm{ms}^{2} \mathrm{i}^{6} \mathrm{~A} 37$ modification or that the CDKAL1 homolog can act on both $\mathrm{i}^{6} \mathrm{~A}$ and $\mathrm{t}^{6} \mathrm{~A}$ substrates. The $\mathrm{ms}^{2} \mathrm{i}^{6} \mathrm{~A}$ modification provides stability in interactions between tRNA and mRNA and the ribosome, and thus not surprisingly, defects in its biosynthetic enzyme MiaB result in translational frameshifting. In S. typhimurium, mutations within the miaB gene, rendering it inactive, demonstrated that absence of the $\mathrm{ms}^{2}$-modification on A37 reduced decoding efficiency of amber suppressor tRNA, and furthermore, affected regulation of several operons encoding components of amino acid biosynthesis [33].

Though present in B. subtilis, the MtaB (YqeV, TmtB) enzyme, and its product, the $\mathrm{ms}^{2} \mathrm{t}^{6} \mathrm{~A}$ modification, are not found in E. coli [111,112]. Upon discovery of the role of MtaB in B. subtilis $\mathrm{ms}^{2} \mathrm{t}^{6} \mathrm{~A}$ methylthiolation, the authors were interested in determining what governed the specificity of the $\mathrm{MiaB}$ and $\mathrm{MtaB}$ enzymes, as they catalyze strikingly similar reactions and exhibit a high degree of sequence similarity, yet simultaneously are specific for their respective $i^{6} \mathrm{~A}$ and $\mathrm{t}^{6} \mathrm{~A}$ tRNA substrates. This prompted the generation of chimeric proteins in which the domains of MiaB and MtaB were switched, and subsequently tested for their competency to methylthiolate each other's $N^{6}$-modified tRNA substrates. These experiments, along with bioinformatic amino acid sequence analysis, led to the proposal that the radical SAM and/or N-terminal domains, but not the C-terminal TRAM domain were responsible for substrate recognition. In the same study, the authors also demonstrated that compared to its E. coli ortholog, B. subtilis MiaB is more restrictive in its $\mathrm{i}^{6} \mathrm{~A} 37$-modified tRNA substrate recognition. E. coli MiaB is capable of modifying non-natural substrates such as an $\mathrm{i}^{6} \mathrm{~A} 37$-containing $17 \mathrm{bp}$ oligonucleotide mimicking the anticodon of a natural substrate, tRNA $^{\text {Phe }}$, as well as several mature tRNAs mutated to become isopentylated by MiaA. Although comparison of tRNA substrate sequences across species enabled speculation as to the determinants of enzyme recognition, the 
difference in $\mathrm{ms}^{2} \mathrm{i}^{6} \mathrm{~A}$ prevalence attributed to tRNA substrate sequence versus differences in the enzymes remains to be determined. Interestingly, $\mathrm{ms}^{2} \mathrm{i}^{6} \mathrm{~A}$ abundance is associated with sporulation in B. subtilis, and considering the lack of this process in E. coli, has been hypothesized to be a source of divergence between the species [111]. Recent advances in techniques for analysis of modification levels, as well as precise location of modifications within tRNA isoacceptors will enable more thorough characterization of the enzymes involved in these pathways.

Initial studies involving methylthiolation by MTTases showed inefficiency of these enzymes in catalyzing multiple turnover reactions. Based on the analysis of cofactors before and after reaction cycles, the mechanism for tRNA A37 methylthiolation was postulated to involve destruction (i.e., sacrifice) of the MTTase's auxiliary cluster to provide the sulfur atom for thiolation of A37, followed by methylation of that sulfur in a polar $\mathrm{S}_{\mathrm{N}} 2$ reaction. This mechanism is consistent with that utilized by the radical SAM enzymes LipA and BioB in biosynthesis of lipoic acid and biotin, respectively [202,203]. Although the aforementioned mechanism was supported by experimental evidence $[16,17,109,204]$, and similar to that of related enzymes, the inherent instability of [Fe-S] cluster in radical SAM enzymes may have perhaps confounded results by indicating a sacrificial role for the auxiliary [Fe-S] cluster in these MTTases. Recent studies have provided evidence for an alternate distinct mechanism in which the sulfur is not obtained from the [4Fe-4S] cluster itself, but rather a sulfide ion previously ligated to the only Fe atom on the auxiliary cluster that is not coordinated by a Cys residue (Figure 5). Although the source of the sulfide ion is as yet unknown, the presumption is that it is obtained from free cysteine.

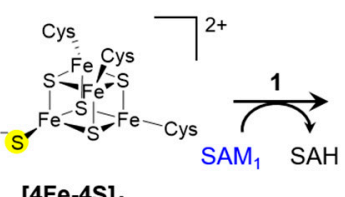

$[4 \mathrm{Fe}-4 \mathrm{~S}]_{\text {Aux }}$

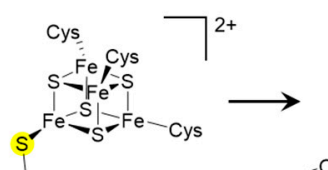

${ }_{\mathrm{CH}_{3}}$
HO<smiles>[R]Nc1nc(CCC)nc2c1ncn2C(C)CC</smiles>

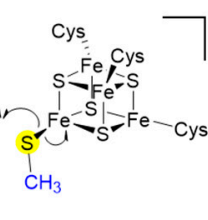

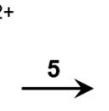<smiles>CSc1ncc2ncn(C(O)C(O)C(O)CO)c2n1</smiles>

4<smiles>O=C(O[Ga])OC1CC2CC1C2</smiles>

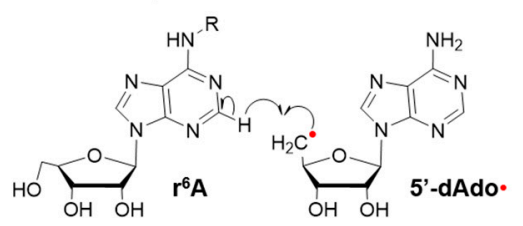

3

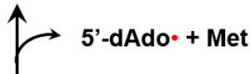

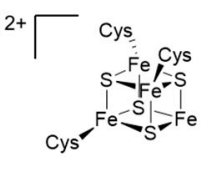

$[4 \mathrm{Fe}-4 \mathrm{~S}]_{\text {RadSAM }}$

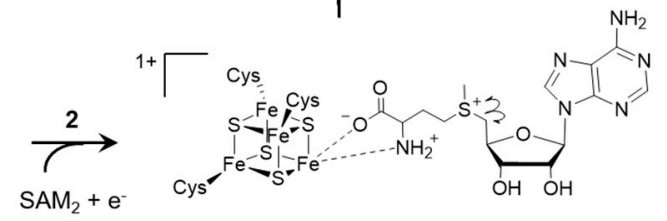

Figure 5. Proposed mechanism for methylthiolation of tRNA A37 by MiaB and MtaB. In the first step of the mechanism (1), a methyl group (in blue) is transferred from S-adenosylmethionine (SAM) to a sulfide ion (in yellow) previously ligated to the free Fe on the auxiliary [4Fe-4S] cluster. In steps 2 and 3 , the radical SAM [4Fe-4S] cluster, via its free Fe, binds a second SAM molecule, which subsequently undergoes reductive cleavage, releasing methionine and the $5^{\prime}$-deoxyadenosyl radical $\left(5^{\prime}\right.$-dAdo•, in red). Next (4), the highly reactive $5^{\prime}$-dAdo• abstracts a $\mathrm{H}$ from C2 of tRNA r ${ }^{6} \mathrm{~A} 37$ (previously modified at the $\mathrm{C} 6$ position), generating a $\mathrm{r}^{6} \mathrm{~A} 37 \bullet$ radical at $\mathrm{C} 2$ and releasing $5^{\prime}$-deoxyadenosine $\left(5^{\prime}\right.$-dAdo). In the final step (5), the $\mathrm{r}^{6} \mathrm{~A} 37 \bullet$ radical facilitates transfer of the methylthio group from the auxiliary $4 \mathrm{Fe}-4 \mathrm{~S}$ to $\mathrm{C} 2$ of $\mathrm{r}^{6} \mathrm{~A} 37$, yielding the final $\mathrm{ms}^{2} \mathrm{r}^{6} \mathrm{~A} 37$ product. In this legend, "free $\mathrm{Fe}^{\text {" refers to }}$ the only Fe within the cluster not ligated to a Cys residue within the enzyme. 
There are two major branches for the $\mathrm{ms}^{2} \mathrm{~A} 37$ mechanism, each involving one of the MTTase clusters. First, the sulfide ion ligated to the auxiliary cluster becomes methylated in a reaction using SAM and resulting in s-adenosylhomocysteine(SAH) as a byproduct. Meanwhile, the "free" Fe on the radical SAM cluster is coordinated by a second molecule of SAM, and reductive cleavage of this SAM molecule results in release of methionine and more importantly, the $5^{\prime}$-deoxyadenosyl radical, which can abstract an $\mathrm{H}$ from $\mathrm{C} 2$ of $^{6}{ }^{6} \mathrm{~A} 37\left(\mathrm{i}^{6}{ }_{-}, \mathrm{t}^{6}{ }_{-}\right.$, and $\mathrm{ct}^{6}$-modifications are represented here and in Figure 5 as $\mathrm{r}^{6}$ - for simplicity), yielding a $\mathrm{r}^{6} \mathrm{~A} 37$ radical. Finally, the two branches are joined together, as the $r^{6} \mathrm{~A} 37$ radical enables transfer of the methylthio group from the auxiliary cluster to its $\mathrm{C} 2$ position [13-15,200,205].

\section{Interconnectivity between tRNA Modification and Biosynthesis of Other Cofactors}

Unlike the thio-modifications that are conserved throughout all kingdoms, it appears that some thio-modifications are not necessary in eukaryotes. For instance, $\mathrm{s}^{2} \mathrm{C}$ is only observed in bacterial tRNA ${ }^{\text {Ser }}$ and tRNA ${ }^{\text {Arg }}$ [63] and it is absent in several species of bacteria including the model Gram-positive bacterium B. subtilis. Furthermore, $\mathrm{s}^{4} \mathrm{U}$ is likely the most abundant thionucleoside in prokaryotic tRNA [62], present in 25 of the 40 tRNA isoacceptors in E. coli [3], yet it is absent in eukaryotes. These modifications are not strictly required for cellular growth, but rather, impact downstream translational events by altering tRNA structural stability. In particular, the thiol modification from cytosine at position 32 enhances the interaction between the first (C32) and last (A38) nucleotides in the anticodon loop and results in optimal decoding efficiency [63]. $\mathrm{s}^{4} \mathrm{U}^{\prime} \mathrm{s}$ photochemical reaction, as discussed above, leads to disordered tRNA structure and reduces the cell growth rate by triggering the stringent response [62]. Recent studies have revealed that thio-modifications participate in other cellular processes, including metabolism, stress response, and regulatory functions [24]. Several recent models have proposed interconnectivity between biosynthesis of thionucleosides and other thiocofactors in bacteria, providing another potential regulatory mechanism for thiocofactor biosynthesis [178,179]. In E. coli, $\mathrm{s}^{2} \mathrm{C}$ and $\mathrm{ms}^{2} \mathrm{i}^{6} \mathrm{~A}$ biosynthetic pathways utilize [Fe-S] cluster dependent proteins, as do the pathways for $\mathrm{ms}^{2} \mathrm{i}^{6} \mathrm{~A}$ and $\mathrm{ms}^{2} \mathrm{t}^{6} \mathrm{~A}$ biosyntheses in $B$. subtilis. It is likely that levels of such modifications are linked to the competency of [Fe-S] cluster biogenesis (Table 1), which is essential for bacterial survival and sensitive to environmental stresses. In addition, a non-thiolation modification, queuosine at the tRNA (His, Asp, Asn, Glu and Tyr) wobble position is synthesized in 8 enzymatic steps, with the final step catalyzed by the [Fe-S] cluster and cobalamin-dependent enzyme QueG [103]. This modification has become an element to assess the global biogenesis of [Fe-S] clusters. Although $s^{4} U$ and $x^{5} s^{2} \mathrm{U}$ formation are not dependent on [Fe-S] clusters, their sulfur mobilization pathways are also shared with those of thiamine and molybdenum cofactor biosyntheses, respectively. Thus, deficiencies in these two tRNA modifications usually coincide with depletion of thiamine and/or molybdenum cofactor simultaneously [11]. An interesting implication of the model for thiocofactor interconnectivity in E. coli is the potential for a hierarchical order of sulfur delivery to various thiocofactors, mediated by competition between sulfur acceptor proteins for interaction with the cysteine desulfurase, IscS. This competition could be affected by many variables, including but not limited to, the binding affinity of IscS for its various sulfur acceptor proteins, overlapping regions of interaction on IscS, and expression levels of the sulfur acceptor protein substrates. Similarly, sulfur flux to various pathways could also be regulated by expression levels of downstream pathway components, like MnmA for $\mathrm{s}^{2} \mathrm{U}$ formation, or the final tRNA substrate itself. In contrast, B. subtilis has adopted an alternative strategy by encoding several cysteine desulfurases with devoted functions in sulfur mobilization. The mechanism for regulating sulfur incorporation into tRNA is partially decoupled from the biosynthesis of other sulfur cofactors in this Gram-positive bacterium.

Although recent work has allowed us to take significant leaps in our understanding of bacterial thiocofactor formation, several additional questions remain regarding thionucleoside biosynthesis in both systems. Though the mechanism for uridine adenylation and thiolation has been proposed, the exact residues initiating adenylation are still unclear for ThiI and MnmA. The dependency of 
ATP-binding for the catalytic sulfurtransferase competency of MnmA, whether structural or otherwise, which is dispensable for Thil, has yet to be determined. In both MnmA and Thil reaction mechanisms, the end of each thiouridylase's catalytic cycle is marked with the formation of a disulfide bond, enforcing the requirement of a reductive step for the regeneration of the enzyme. This reaction scheme poses a question regarding the identity of the physiological reducing agent participating in these biosynthetic pathways. Equally fascinating, and yet not fully understood, are the structural and mechanistic determinants of the MTTase enzymes and their tRNA substrates governing specificity in $\mathrm{tRNA}$ modification reactions. Likewise, the identity of the sulfur source for A37 modifications and reaction schemes allowing for enzyme regeneration upon multiple turnovers still represent challenges when uncovering details about these pathways. Lastly, the capacity of involvement of the cysteine desulfurase and sulfur transfer enzymes, CsdA and CsdE, in formation of the non-sulfur containing $\mathrm{ct}^{6} \mathrm{~A}$ modification still remains enigmatic.

Another emerging and exciting aspect in this area of study besides complex and interconnected biosynthetic pathways, is the identification of additional functions of tRNA in signaling metabolic and environmental changes and their consequent roles in regulating translation. The discovery of new roles for tRNA in cellular processes is greatly facilitated by the development of systems-levels approaches for assessing tRNA modification fluctuations in response to various stress and growth conditions, which was first utilized in yeast [41]. A more recent application of the systems-level approach by the same group revealed that a similar phenomenon occurs in Mycobacterium bovis BCG, which reprograms 40 modified nucleosides in response to hypoxia, consequently affecting translation of various genes involved in bacterial persistence [151]. A detailed investigation was conducted to understand the nearly 8-fold increase in $\mathrm{cmo}^{5} \mathrm{U}$ observed upon exposure to hypoxia, but this experiment also revealed a significant change in thionucleosides that has yet to be explored. Importantly, $\mathrm{ms}^{2} \mathrm{i}^{6} \mathrm{~A}$ levels increased $>5$-fold in response to hypoxia, with a corresponding depletion of $i^{6} \mathrm{~A}$, whereas $\mathrm{ms}^{2} \mathrm{t}^{6} \mathrm{~A}$ was completely depleted during hypoxia and a concomitant 2-fold increase in $\mathrm{t}^{6} \mathrm{~A}$ and $\mathrm{ct}^{6} \mathrm{~A}$ was observed. U34 thiolation levels changed drastically in response to hypoxia as well, with a 4- and 10.6-fold increase in $\mathrm{s}^{2} \mathrm{Um}$ and $\mathrm{mnm}^{5} \mathrm{~s}^{2} \mathrm{U}$, respectively. Interestingly, hypoxia induced a depletion in $\mathrm{cmnm}^{5} \mathrm{~s}^{2} \mathrm{U}$, in addition to $\mathrm{cmnm}^{5} \mathrm{U}$ and $\mathrm{mnm}^{5} \mathrm{U}$, suggesting that neither branch of U34 modification is impacted by hypoxia, particularly the thiolation branch. Alternatively, thiolation of $\mathrm{s}^{4} \mathrm{U}$ was negatively impacted during hypoxia, as it was completely depleted. For all examples given above, the levels of modified nucleosides returned back to normal levels upon reaeration, albeit some more quickly than others. Collectively, these results indicate that such methodology can potentially enable predictions of proteins that are required during hypoxia and bacterial persistence by means of identifying genes enriched in codons read by tRNAs containing modifications that are upregulated during these conditions. Similarly, it could suggest mechanisms for exiting persistence, based on tRNA modifications that are depleted during hypoxia, yet increase drastically within the first stage of reaeration.

Recent technological advances on methods for detection and quantification of relative levels of tRNA modifications propelled by the rapid expansion of the inventory of bacterial species with sequenced genomes has provided valuable tools for uncovering new functions of sulfur decorations on tRNA. Post-transcriptional modifications on tRNA are not only important in guaranteeing the accurate decoding of genetic information but also connecting the universal process of translation to other metabolic pathways involving the synthesis of protein cofactors as well as cellular adaptations to environmental and nutritional changes.

Acknowledgments: The research in the laboratory of P.C.D.S. is supported by National Science Foundation MCB-1054623.

Author Contributions: C.Z., K.A.B., and P.C.D.S. wrote the manuscript.

Conflicts of Interest: The authors declare no conflict of interest. 


\section{References}

1. Mccloskey, J.A.; Nishimura, S. Modified nucleosides in transfer-RNA. Acc. Chem. Res. 1977, 10, $403-410$. [CrossRef]

2. Marbaniang, C.N.; Vogel, J. Emerging roles of rna modifications in bacteria. Curr. Opin. Microbiol. 2016, 30, 50-57. [CrossRef] [PubMed]

3. Machnicka, M.A.; Milanowska, K.; Osman Oglou, O.; Purta, E.; Kurkowska, M.; Olchowik, A.; Januszewski, W.; Kalinowski, S.; Dunin-Horkawicz, S.; Rother, K.M.; et al. Modomics: A database of RNA modification pathways-2013 update. Nucleic Acids Res. 2013, 41, D262-D267. [CrossRef] [PubMed]

4. Phizicky, E.M.; Alfonzo, J.D. Do all modifications benefit all tRNAs? FEBS Lett. 2010, 584, 265-271. [CrossRef] [PubMed]

5. Cantara, W.A.; Crain, P.F.; Rozenski, J.; McCloskey, J.A.; Harris, K.A.; Zhang, X.; Vendeix, F.A.; Fabris, D.; Agris, P.F. The RNA modification database, RNAMDB: 2011 update. Nucleic Acids Res. 2011, 39, D195-D201. [CrossRef] [PubMed]

6. Rodriguez-Hernandez, A.; Spears, J.L.; Gaston, K.W.; Limbach, P.A.; Gamper, H.; Hou, Y.M.; Kaiser, R.; Agris, P.F.; Perona, J.J. Structural and mechanistic basis for enhanced translational efficiency by 2-thiouridine at the tRNA anticodon wobble position. J. Mol. Biol. 2013, 425, 3888-3906. [CrossRef] [PubMed]

7. Jackman, J.E.; Alfonzo, J.D. Transfer RNA modifications: Nature's combinatorial chemistry playground. Wiley Interdiscip. Rev. RNA 2013, 4, 35-48. [CrossRef] [PubMed]

8. Charette, M.; Gray, M.W. Pseudouridine in RNA: What, where, how, and why. IUBMB Life 2000, 49, 341-351. [PubMed]

9. Shigi, N. Biosynthesis and functions of sulfur modifications in tRNA. Front. Genet. 2014, 5, 67. [CrossRef] [PubMed]

10. Shigi, N.; Sakaguchi, Y.; Asai, S.; Suzuki, T.; Watanabe, K. Common thiolation mechanism in the biosynthesis of tRNA thiouridine and sulphur-containing cofactors. EMBO J. 2008, 27, 3267-3278. [CrossRef] [PubMed]

11. Lauhon, C.T. Requirement for IscS in biosynthesis of all thionucleosides in Escherichia coli. J. Bacteriol. 2002, 184, 6820-6829. [CrossRef] [PubMed]

12. Mueller, E.G. Trafficking in persulfides: Delivering sulfur in biosynthetic pathways. Nat. Chem. Biol. 2006, 2, 185-194. [CrossRef] [PubMed]

13. Landgraf, B.J.; Arcinas, A.J.; Lee, K.H.; Booker, S.J. Identification of an intermediate methyl carrier in the radical S-adenosylmethionine methylthiotransferases RimO and MiaB. J. Am. Chem. Soc. 2013, 135, 15404-15416. [CrossRef] [PubMed]

14. Maiocco, S.J.; Arcinas, A.J.; Landgraf, B.J.; Lee, K.H.; Booker, S.J.; Elliott, S.J. Transformations of the FeS clusters of the methylthiotransferases MiaB and RimO, detected by direct electrochemistry. Biochemistry 2016, 55, 5531-5536. [CrossRef] [PubMed]

15. Forouhar, F.; Arragain, S.; Atta, M.; Gambarelli, S.; Mouesca, J.M.; Hussain, M.; Xiao, R.; Kieffer-Jaquinod, S.; Seetharaman, J.; Acton, T.B.; et al. Two Fe-S clusters catalyze sulfur insertion by radical-SAM methylthiotransferases. Nat. Chem. Biol. 2013, 9, 333-338. [CrossRef] [PubMed]

16. Hernandez, H.L.; Pierrel, F.; Elleingand, E.; Garcia-Serres, R.; Huynh, B.H.; Johnson, M.K.; Fontecave, M.; Atta, M. MiaB, a bifunctional radical-s-adenosylmethionine enzyme involved in the thiolation and methylation of tRNA, contains two essential [4Fe-4S] clusters. Biochemistry 2007, 46, 5140-5147. [CrossRef] [PubMed]

17. Pierrel, F.; Douki, T.; Fontecave, M.; Atta, M. MiaB protein is a bifunctional radical-S-adenosylmethionine enzyme involved in thiolation and methylation of tRNA. J. Biol. Chem. 2004, 279, 47555-47563. [CrossRef] [PubMed]

18. Agris, P.F. Bringing order to translation: The contributions of transfer RNA anticodon-domain modifications. EMBO Rep. 2008, 9, 629-635. [CrossRef] [PubMed]

19. Agris, P.F.; Vendeix, F.A.; Graham, W.D. tRNA's wobble decoding of the genome: 40 years of modification. J. Mol. Biol. 2007, 366, 1-13. [CrossRef] [PubMed]

20. Murphy, F.V.T.; Ramakrishnan, V.; Malkiewicz, A.; Agris, P.F. The role of modifications in codon discrimination by tRNA ${ }^{\text {Lys }}$ UUU. Nat. Struct. Mol. Biol. 2004, 11, 1186-1191. [CrossRef] [PubMed] 
21. Ashraf, S.S.; Guenther, R.; Agris, P.F. Orientation of the tRNA anticodon in the ribosomal P-site: Quantitative footprinting with U33-modified, anticodon stem and loop domains. RNA 1999, 5, 1191-1199. [CrossRef] [PubMed]

22. Davis, J.P.; Janjic, N.; Pribnow, D.; Zichi, D.A. Alignment editing and identification of consensus secondary structures for nucleic acid sequences: Interactive use of dot matrix representations. Nucleic Acids Res. 1995, 23, 4471-4479. [CrossRef] [PubMed]

23. Motorin, Y.; Helm, M. tRNA stabilization by modified nucleotides. Biochemistry 2010, 49, $4934-4944$. [CrossRef] [PubMed]

24. El Yacoubi, B.; Bailly, M.; de Crecy-Lagard, V. Biosynthesis and function of posttranscriptional modifications of transfer RNAs. Annu. Rev. Genet. 2012, 46, 69-95. [CrossRef] [PubMed]

25. Nameki, N. Identity elements of $\mathrm{tRNA}^{\text {Thr }}$ towards Saccharomyces cerevisiae threonyl-tRNA synthetase. Nucleic Acids Res. 1995, 23, 2831-2836. [CrossRef] [PubMed]

26. Rudinger, J.; Florentz, C.; Giege, R. Histidylation by yeast HisRs of tRNA or tRNA-like structure relies on residues -1 and 73 but is dependent on the RNA context. Nucleic Acids Res. 1994, 22, 5031-5037. [CrossRef] [PubMed]

27. Shigi, N.; Suzuki, T.; Terada, T.; Shirouzu, M.; Yokoyama, S.; Watanabe, K. Temperature-dependent biosynthesis of 2-thioribothymidine of Thermus thermophilus tRNA. J. Biol. Chem. 2006, 281, 2104-2113. [CrossRef] [PubMed]

28. Pan, T. Adaptive translation as a mechanism of stress response and adaptation. Annu. Rev. Genet. 2013, 47, 121-137. [CrossRef] [PubMed]

29. Dumelin, C.E.; Chen, Y.; Leconte, A.M.; Chen, Y.G.; Liu, D.R. Discovery and biological characterization of geranylated RNA in bacteria. Nat. Chem. Biol. 2012, 8, 913-919. [CrossRef] [PubMed]

30. Tukenmez, H.; Xu, H.; Esberg, A.; Bystrom, A.S. The role of wobble uridine modifications in +1 translational frameshifting in eukaryotes. Nucleic Acids Res. 2015, 43, 9489-9499. [CrossRef]

31. Urbonavicius, J.; Qian, Q.; Durand, J.M.; Hagervall, T.G.; Bjork, G.R. Improvement of reading frame maintenance is a common function for several tRNA modifications. EMBO J. 2001, 20, 4863-4873. [CrossRef] [PubMed]

32. Esberg, B.; Bjork, G.R. The methylthio group $\left(\mathrm{ms}^{2}\right)$ of $N^{6}$-(4-hydroxyisopentenyl)-2-methylthioadenosine $\left(\mathrm{ms}^{2} \mathrm{io}^{6} \mathrm{~A}\right)$ present next to the anticodon contributes to the decoding efficiency of the tRNA. J. Bacteriol. 1995, 177, 1967-1975. [CrossRef] [PubMed]

33. Esberg, B.; Leung, H.C.; Tsui, H.C.; Bjork, G.R.; Winkler, M.E. Identification of the MiaB gene, involved in methylthiolation of isopentenylated A37 derivatives in the tRNA of Salmonella typhimurium and Escherichia coli. J. Bacteriol. 1999, 181, 7256-7265. [PubMed]

34. Connolly, D.M.; Winkler, M.E. Structure of Escherichia coli K-12 MiaA and characterization of the mutator phenotype caused by MiaA insertion mutations. J. Bacteriol. 1991, 173, 1711-1721. [CrossRef] [PubMed]

35. Agris, P.F. Wobble position modified nucleosides evolved to select transfer RNA codon recognition: A modified-wobble hypothesis. Biochimie 1991, 73, 1345-1349. [CrossRef]

36. Crick, F.H. The genetic code: III. Sci. Am. 1966, 215, 55-60. [CrossRef] [PubMed]

37. Ikeuchi, Y.; Shigi, N.; Kato, J.; Nishimura, A.; Suzuki, T. Mechanistic insights into sulfur relay by multiple sulfur mediators involved in thiouridine biosynthesis at tRNA wobble positions. Mol. Cell 2006, 21, 97-108. [CrossRef] [PubMed]

38. Ogle, J.M.; Brodersen, D.E.; Clemons, W.M., Jr.; Tarry, M.J.; Carter, A.P.; Ramakrishnan, V. Recognition of cognate transfer RNA by the 30S ribosomal subunit. Science 2001, 292, 897-902. [CrossRef] [PubMed]

39. Yarian, C.; Townsend, H.; Czestkowski, W.; Sochacka, E.; Malkiewicz, A.J.; Guenther, R.; Miskiewicz, A.; Agris, P.F. Accurate translation of the genetic code depends on tRNA modified nucleosides. J. Biol. Chem. 2002, 277, 16391-16395. [CrossRef]

40. McKenney, K.M.; Alfonzo, J.D. From prebiotics to probiotics: The evolution and functions of tRNA modifications. Life (Basel) 2016, 6, 13. [CrossRef]

41. Laxman, S.; Sutter, B.M.; Wu, X.; Kumar, S.; Guo, X.; Trudgian, D.C.; Mirzaei, H.; Tu, B.P. Sulfur amino acids regulate translational capacity and metabolic homeostasis through modulation of tRNA thiolation. Cell 2013, 154, 416-429. [CrossRef] [PubMed] 
42. Chen, C.; Tuck, S.; Bystrom, A.S. Defects in tRNA modification associated with neurological and developmental dysfunctions in Caenorhabditis elegans elongator mutants. PLoS Genet. 2009, 5, e1000561. [CrossRef]

43. Walker, J.; Kwon, S.Y.; Badenhorst, P.; East, P.; McNeill, H.; Svejstrup, J.Q. Role of elongator subunit Elp3 in Drosophila melanogaster larval development and immunity. Genetics 2011, 187, 1067-1075. [CrossRef] [PubMed]

44. Guan, M.X.; Yan, Q.; Li, X.; Bykhovskaya, Y.; Gallo-Teran, J.; Hajek, P.; Umeda, N.; Zhao, H.; Garrido, G.; Mengesha, E.; et al. Mutation in TRMU related to transfer RNA modification modulates the phenotypic expression of the deafness-associated mitochondrial $12 \mathrm{~S}$ ribosomal RNA mutations. Am. J. Hum. Genet. 2006, 79, 291-302. [CrossRef] [PubMed]

45. Kirino, Y.; Yasukawa, T.; Ohta, S.; Akira, S.; Ishihara, K.; Watanabe, K.; Suzuki, T. Codon-specific translational defect caused by a wobble modification deficiency in mutant tRNA from a human mitochondrial disease. Proc. Natl. Acad. Sci. USA 2004, 101, 15070-15075. [CrossRef] [PubMed]

46. Kirino, Y.; Suzuki, T. Human mitochondrial diseases associated with tRNA wobble modification deficiency. RNA Biol. 2005, 2, 41-44. [CrossRef]

47. Yasukawa, T.; Suzuki, T.; Ishii, N.; Ueda, T.; Ohta, S.; Watanabe, K. Defect in modification at the anticodon wobble nucleotide of mitochondrial tRNA ${ }^{\text {Lys }}$ )with the MERRF encephalomyopathy pathogenic mutation. FEBS Lett. 2000, 467, 175-178. [CrossRef]

48. Yasukawa, T.; Suzuki, T.; Ishii, N.; Ohta, S.; Watanabe, K. Wobble modification defect in tRNA disturbs codon-anticodon interaction in a mitochondrial disease. EMBO J. 2001, 20, 4794-4802. [CrossRef] [PubMed]

49. Yasukawa, T.; Kirino, Y.; Ishii, N.; Holt, I.J.; Jacobs, H.T.; Makifuchi, T.; Fukuhara, N.; Ohta, S.; Suzuki, T.; Watanabe, K. Wobble modification deficiency in mutant tRNAs in patients with mitochondrial diseases. FEBS Lett. 2005, 579, 2948-2952. [CrossRef] [PubMed]

50. Helm, M.; Alfonzo, J.D. Posttranscriptional RNA modifications: Playing metabolic games in a cell's chemical legoland. Chem. Biol. 2014, 21, 174-185. [CrossRef] [PubMed]

51. Noma, A.; Sakaguchi, Y.; Suzuki, T. Mechanistic characterization of the sulfur-relay system for eukaryotic 2-thiouridine biogenesis at tRNA wobble positions. Nucleic Acids Res. 2009, 37, 1335-1352. [CrossRef] [PubMed]

52. Nilsson, K.; Lundgren, H.K.; Hagervall, T.G.; Bjork, G.R. The cysteine desulfurase IscS is required for synthesis of all five thiolated nucleosides present in tRNA from Salmonella enterica serovar Typhimurium. J. Bacteriol. 2002, 184, 6830-6835. [CrossRef] [PubMed]

53. Lauhon, C.T.; Kambampati, R. The IscS gene in Escherichia coli is required for the biosynthesis of 4-thiouridine, thiamin, and NAD. J. Biol. Chem. 2000, 275, 20096-20103. [CrossRef] [PubMed]

54. Schwartz, C.J.; Djaman, O.; Imlay, J.A.; Kiley, P.J. The cysteine desulfurase, IscS, has a major role in in vivo Fe-S cluster formation in Escherichia coli. Proc. Natl. Acad. Sci. USA 2000, 97, 9009-9014. [CrossRef] [PubMed]

55. Torres, A.G.; Batlle, E.; Ribas de Pouplana, L. Role of tRNA modifications in human diseases. Trends Mol. Med. 2014, 20, 306-314. [CrossRef] [PubMed]

56. Wei, F.Y.; Suzuki, T.; Watanabe, S.; Kimura, S.; Kaitsuka, T.; Fujimura, A.; Matsui, H.; Atta, M.; Michiue, H.; Fontecave, M.; et al. Deficit of tRNA ${ }^{\text {Lys }}$ modification by CDKAL1 causes the development of type 2 diabetes in mice. J. Clin. Investig. 2011, 121, 3598-3608. [CrossRef] [PubMed]

57. Wei, F.Y.; Zhou, B.; Suzuki, T.; Miyata, K.; Ujihara, Y.; Horiguchi, H.; Takahashi, N.; Xie, P.; Michiue, H.; Fujimura, A.; et al. Cdk5rap1-mediated 2-methylthio modification of mitochondrial tRNAs governs protein translation and contributes to myopathy in mice and humans. Cell Metab. 2015, 21, 428-442. [CrossRef] [PubMed]

58. Giege, R. Toward a more complete view of tRNA biology. Nat. Struct. Mol. Biol. 2008, 15, 1007-1014. [CrossRef] [PubMed]

59. Miyauchi, K.; Kimura, S.; Suzuki, T. A cyclic form of $N^{6}$-threonylcarbamoyladenosine as a widely distributed tRNA hypermodification. Nat. Chem. Biol. 2013, 9, 105-111. [CrossRef] [PubMed]

60. Favre, A.; Michelson, A.M.; Yaniv, M. Photochemistry of 4-thiouridine in Escherichia coli transfer RNA1Val. J. Mol. Biol. 1971, 58, 367-379. [CrossRef]

61. Thomas, G.; Favre, A. 4-thiouridine as the target for near-ultraviolet light induced growth delay in Escherichia coli. Biochem. Biophys. Res. Commun. 1975, 66, 1454-1461. [CrossRef] 
62. Mueller, E.G.; Buck, C.J.; Palenchar, P.M.; Barnhart, L.E.; Paulson, J.L. Identification of a gene involved in the generation of 4-thiouridine in tRNA. Nucleic Acids Res. 1998, 26, 2606-2610. [CrossRef] [PubMed]

63. Jager, G.; Leipuviene, R.; Pollard, M.G.; Qian, Q.; Bjork, G.R. The conserved Cys- $X_{1}-X_{2}-C_{y s}$ motif present in the TtcA protein is required for the thiolation of cytidine in position 32 of tRNA from Salmonella enterica serovar Typhimurium. J. Bacteriol. 2004, 186, 750-757. [CrossRef] [PubMed]

64. Mueller, E.G.; Palenchar, P.M.; Buck, C.J. The role of the cysteine residues of ThiI in the generation of 4-thiouridine in tRNA. J. Biol. Chem. 2001, 276, 33588-33595. [CrossRef]

65. You, D.; Xu, T.; Yao, F.; Zhou, X.; Deng, Z. Direct evidence that ThiI is an ATP pyrophosphatase for the adenylation of uridine in 4-thiouridine biosynthesis. Chembiochem 2008, 9, 1879-1882. [CrossRef] [PubMed]

66. Martinez-Gomez, N.C.; Palmer, L.D.; Vivas, E.; Roach, P.L.; Downs, D.M. The rhodanese domain of ThiI is both necessary and sufficient for synthesis of the thiazole moiety of thiamine in Salmonella enterica. J. Bacteriol. 2011, 193, 4582-4587. [CrossRef] [PubMed]

67. Neumann, P.; Lakomek, K.; Naumann, P.T.; Erwin, W.M.; Lauhon, C.T.; Ficner, R. Crystal structure of a 4-thiouridine synthetase-RNA complex reveals specificity of tRNA U8 modification. Nucleic Acids Res. 2014, 42, 6673-6685. [CrossRef] [PubMed]

68. Rajakovich, L.J.; Tomlinson, J.; Dos Santos, P.C. Functional analysis of Bacillus subtilis genes involved in the biosynthesis of 4-thiouridine in tRNA. J. Bacteriol. 2012, 194, 4933-4940. [CrossRef] [PubMed]

69. Waterman, D.G.; Ortiz-Lombardia, M.; Fogg, M.J.; Koonin, E.V.; Antson, A.A. Crystal structure of Bacillus anthracis ThiI, a tRNA-modifying enzyme containing the predicted RNA-binding thump domain. J. Mol. Biol. 2006, 356, 97-110. [CrossRef]

70. Kambampati, R.; Lauhon, C.T. Mnma and IscS are required for in vitro 2-thiouridine biosynthesis in Escherichia coli. Biochemistry 2003, 42, 1109-1117. [CrossRef] [PubMed]

71. Numata, T.; Fukai, S.; Ikeuchi, Y.; Suzuki, T.; Nureki, O. Structural basis for sulfur relay to RNA mediated by heterohexameric TusBCD complex. Structure 2006, 14, 357-366. [CrossRef] [PubMed]

72. Black, K.A.; Dos Santos, P.C. An abreviated pathway for the biosynthesis of 2-thiouridine in Bacillus subtilis. J. Bacteriol. 2015, 197, 1952-1962. [CrossRef] [PubMed]

73. Bujnicki, J.M.; Oudjama, Y.; Roovers, M.; Owczarek, S.; Caillet, J.; Droogmans, L. Identification of a bifunctional enzyme MnmC involved in the biosynthesis of a hypermodified uridine in the wobble position of tRNA. RNA 2004, 10, 1236-1242. [CrossRef] [PubMed]

74. Kitamura, A.; Nishimoto, M.; Sengoku, T.; Shibata, R.; Jager, G.; Bjork, G.R.; Grosjean, H.; Yokoyama, S.; Bessho, Y. Characterization and structure of the Aquifex aeolicus protein DUF752: A bacterial tRNA-methyltransferase (MnmC2) functioning without the usually fused oxidase domain (MnmC1). J. Biol. Chem. 2012, 287, 43950-43960. [CrossRef] [PubMed]

75. Yim, L.; Moukadiri, I.; Bjork, G.R.; Armengod, M.E. Further insights into the tRNA modification process controlled by proteins MnmE and GidA of Escherichia coli. Nucleic Acids Res. 2006, 34, 5892-5905. [CrossRef] [PubMed]

76. Moukadiri, I.; Prado, S.; Piera, J.; Velazquez-Campoy, A.; Bjork, G.R.; Armengod, M.E. Evolutionarily conserved proteins MnmE and GidA catalyze the formation of two methyluridine derivatives at tRNA wobble positions. Nucleic Acids Res. 2009, 37, 7177-7193. [CrossRef] [PubMed]

77. Cabedo, H.; Macian, F.; Villarroya, M.; Escudero, J.C.; Martinez-Vicente, M.; Knecht, E.; Armengod, M.E. The Escherichia coli TrmE (MnmE) gene, involved in tRNA modification, codes for an evolutionarily conserved GTPase with unusual biochemical properties. EMBO J. 1999, 18, 7063-7076. [CrossRef]

78. Martinez-Vicente, M.; Yim, L.; Villarroya, M.; Mellado, M.; Perez-Paya, E.; Bjork, G.R.; Armengod, M.E. Effects of mutagenesis in the switch I region and conserved arginines of Escherichia coli MnmE protein, a gtpase involved in tRNA modification. J. Biol. Chem. 2005, 280, 30660-30670. [CrossRef] [PubMed]

79. Veres, Z.; Stadtman, T.C. A purified selenophosphate-dependent enzyme from Salmonella typhimurium catalyzes the replacement of sulfur in 2-thiouridine residues in tRNAs with selenium. Proc. Natl. Acad. Sci. USA 1994, 91, 8092-8096. [CrossRef] [PubMed]

80. Wolfe, M.D.; Ahmed, F.; Lacourciere, G.M.; Lauhon, C.T.; Stadtman, T.C.; Larson, T.J. Functional diversity of the rhodanese homology domain-The Escherichia coli YbbB gene encodes a selenophosphate-dependent tRNA 2-selenouridine synthase. J. Biol. Chem. 2004, 279, 1801-1809. [CrossRef]

81. Jager, G.; Chen, P.; Bjork, G.R. Transfer RNA bound to mnmh protein is enriched with geranylated tRNA-A possible intermediate in its selenation? PLOS ONE 2016, 11, e0153488. [CrossRef] [PubMed] 
82. Veres, Z.; Tsai, L.; Scholz, T.D.; Politino, M.; Balaban, R.S.; Stadtman, T.C. Synthesis of 5-methylaminomethyl2-selenouridine in tRNAs: ${ }^{31} \mathrm{P}$ NMR studies show the labile selenium donor synthesized by the seld gene product contains selenium bonded to phosphorus. Proc. Natl. Acad. Sci. USA 1992, 89, 2975-2979. [CrossRef] [PubMed]

83. Sierant, M.; Leszczynska, G.; Sadowska, K.; Dziergowska, A.; Rozanski, M.; Sochacka, E.; Nawrot, B. $S$-geranyl-2-thiouridine wobble nucleosides of bacterial tRNAs; chemical and enzymatic synthesis of S-geranylated-RNAs and their physicochemical characterization. Nucleic Acids Res. 2016, 44, 10986-10998. [CrossRef] [PubMed]

84. Lopez-Estepa, M.; Arda, A.; Savko, M.; Round, A.; Shepard, W.E.; Bruix, M.; Coll, M.; Fernandez, F.J.; Jimenez-Barbero, J.; Vega, M.C. The crystal structure and small-angle X-ray analysis of CsdL/TcdA reveal a new tRNA binding motif in the MoeB/E1 superfamily. PLoS One 2015, 10, e0118606. [CrossRef] [PubMed]

85. Kim, S.; Lee, H.; Park, S. The structure of Escherichia coli TcdA (also known as CsdL) reveals a novel topology and provides insight into the tRNA binding surface required for $N^{6}$-threonylcarbamoyladenosine dehydratase activity. J. Mol. Biol. 2015, 427, 3074-3085. [CrossRef] [PubMed]

86. Kim, S.; Kim, K.Y.; Park, J.K.; Lee, B.I.; Kim, Y.G.; Park, S. Overproduction, crystallization and preliminary X-ray crystallographic analysis of Escherichia coli tRNA $N^{6}$-threonylcarbamoyladenosine dehydratase. Acta Crystallogr. F Struct. Biol. Commun. 2014, 70, 1517-1520. [CrossRef] [PubMed]

87. Matuszewski, M.; Wojciechowski, J.; Miyauchi, K.; Gdaniec, Z.; Wolf, W.M.; Suzuki, T.; Sochacka, E. A hydantoin isoform of cyclic $N^{6}$-threonylcarbamoyladenosine $\left(\mathrm{ct}^{6} \mathrm{~A}\right)$ is present in tRNAs. Nucleic Acids Res. 2016. [CrossRef] [PubMed]

88. Kang, B.I.; Miyauchi, K.; Matuszewski, M.; D’Almeida, G.S.; Rubio, M.A.; Alfonzo, J.D.; Inoue, K.; Sakaguchi, Y.; Suzuki, T.; Sochacka, E.; et al. Identification of 2-methylthio cyclic $N^{6}$-threonylcarbamoyladenosine $\left(\mathrm{ms}^{2} \mathrm{ct}^{6} \mathrm{~A}\right)$ as a novel RNA modification at position 37 of tRNAs. Nucleic Acids Res. 2016. [CrossRef] [PubMed]

89. Shigi, N.; Sakaguchi, Y.; Suzuki, T.; Watanabe, K. Identification of two tRNA thiolation genes required for cell growth at extremely high temperatures. J. Biol. Chem. 2006, 281, 14296-14306. [CrossRef]

90. Shigi, N. Posttranslational modification of cellular proteins by a ubiquitin-like protein in bacteria. J. Biol. Chem. 2012, 287, 17568-17577. [CrossRef] [PubMed]

91. Sakaguchi, Y.; Miyauchi, K.; Kang, B.I.; Suzuki, T. Nucleoside analysis by hydrophilic interaction liquid chromatography coupled with mass spectrometry. Methods Enzymol. 2015, 560, 19-28.

92. Watanabe, K.; Shinma, M.; Oshima, T.; Nishimura, S. Heat-induced stability of tRNA from an extreme thermophile, Thermus thermophilus. Biochem. Biophys. Res. Commun. 1976, 72, 1137-1144. [CrossRef]

93. Kowalak, J.A.; Dalluge, J.J.; McCloskey, J.A.; Stetter, K.O. The role of posttranscriptional modification in stabilization of transfer RNA from hyperthermophiles. Biochemistry 1994, 33, 7869-7876. [CrossRef] [PubMed]

94. Bouvier, D.; Labessan, N.; Clemancey, M.; Latour, J.M.; Ravanat, J.L.; Fontecave, M.; Atta, M. TtcA a new tRNA-thioltransferase with an Fe-S cluster. Nucleic Acids Res. 2014, 42, 7960-7970. [CrossRef] [PubMed]

95. Frey, B.; McCloskey, J.; Kersten, W.; Kersten, H. New function of vitamin B12: Cobamide-dependent reduction of epoxyqueuosine to queuosine in tRNAs of Escherichia coli and Salmonella typhimurium. J. Bacteriol. 1988, 170, 2078-2082. [CrossRef] [PubMed]

96. Miles, Z.D.; Roberts, S.A.; McCarty, R.M.; Bandarian, V. Biochemical and structural studies of 6-carboxy-5,6,7,8-tetrahydropterin synthase reveal the molecular basis of catalytic promiscuity within the tunnel-fold superfamily. J. Biol. Chem. 2014, 289, 23641-23652. [CrossRef] [PubMed]

97. Van Lanen, S.G.; Reader, J.S.; Swairjo, M.A.; de Crecy-Lagard, V.; Lee, B.; Iwata-Reuyl, D. From cyclohydrolase to oxidoreductase: Discovery of nitrile reductase activity in a common fold. Proc. Natl. Acad. Sci. USA 2005, 102, 4264-4269. [CrossRef]

98. Miles, Z.D.; McCarty, R.M.; Molnar, G.; Bandarian, V. Discovery of epoxyqueuosine (oQ) reductase reveals parallels between halorespiration and tRNA modification. Proc. Natl. Acad. Sci. USA 2011, 108, 7368-7372. [CrossRef] [PubMed]

99. McCarty, R.M.; Somogyi, A.; Bandarian, V. Escherichia coli QueD is a 6-carboxy-5,6,7,8-tetrahydropterin synthase. Biochemistry 2009, 48, 2301-2303. [CrossRef] [PubMed]

100. Okada, N.; Noguchi, S.; Kasai, H.; Shindo-Okada, N.; Ohgi, T.; Goto, T.; Nishimura, S. Novel mechanism of post-transcriptional modification of tRNA. Insertion of bases of $Q$ precursors into tRNA by a specific tRNA transglycosylase reaction. J. Biol. Chem. 1979, 254, 3067-3073. [PubMed] 
101. Phillips, G.; El Yacoubi, B.; Lyons, B.; Alvarez, S.; Iwata-Reuyl, D.; de Crecy-Lagard, V. Biosynthesis of 7-deazaguanosine-modified tRNA nucleosides: A new role for GTP cyclohydrolase I. J. Bacteriol. 2008, 190, 7876-7884. [CrossRef]

102. Slany, R.K.; Bosl, M.; Kersten, H. Transfer and isomerization of the ribose moiety of adomet during the biosynthesis of queuosine tRNAs, a new unique reaction catalyzed by the QueA protein from Escherichia coli. Biochimie 1994, 76, 389-393. [CrossRef]

103. Miles, Z.D.; Myers, W.K.; Kincannon, W.M.; Britt, R.D.; Bandarian, V. Biochemical and spectroscopic studies of epoxyqueuosine reductase: A novel iron-sulfur cluster- and cobalamin-containing protein involved in the biosynthesis of queuosine. Biochemistry 2015, 54, 4927-4935. [CrossRef]

104. McCarty, R.M.; Krebs, C.; Bandarian, V. Spectroscopic, steady-state kinetic, and mechanistic characterization of the radical SAM enzyme QueE, which catalyzes a complex cyclization reaction in the biosynthesis of 7-deazapurines. Biochemistry 2013, 52, 188-198. [CrossRef] [PubMed]

105. McCarty, R.M.; Somogyi, A.; Lin, G.; Jacobsen, N.E.; Bandarian, V. The deazapurine biosynthetic pathway revealed: In vitro enzymatic synthesis of $\mathrm{PreQ}_{0}$ from guanosine $5^{\prime}$-triphosphate in four steps. Biochemistry 2009, 48, 3847-3852. [CrossRef] [PubMed]

106. Reader, J.S.; Metzgar, D.; Schimmel, P.; de Crecy-Lagard, V. Identification of four genes necessary for biosynthesis of the modified nucleoside queuosine. J. Biol. Chem. 2004, 279, 6280-6285. [CrossRef] [PubMed]

107. Benitez-Paez, A.; Villarroya, M.; Armengod, M.E. The Escherichia coli RlmN methyltransferase is a dual-specificity enzyme that modifies both rRNA and tRNA and controls translational accuracy. RNA 2012, 18, 1783-1795. [CrossRef] [PubMed]

108. Saneyoshi, M.; Oashi, Z.; Harada, F.; Nishimura, S. Isolation and characterization of 2-methyladenosine from Escherichia coli tRNA Glu 2, tRNA Asp 1, tRNA His 1 and tRNA Arg. Biochim. Biophys. Acta 1972, 262, 1-10. [CrossRef]

109. Pierrel, F.; Bjork, G.R.; Fontecave, M.; Atta, M. Enzymatic modification of tRNAs: MiaB is an iron-sulfur protein. J. Biol. Chem. 2002, 277, 13367-13370. [CrossRef]

110. Durand, J.M.B.; Bjork, G.R.; Kuwae, A.; Yoshikawa, M.; Sasakawa, C. The modified nucleoside 2-methylthio- $N^{6}$-isopentenyladenosine in tRNA of shigella flexneri is required for expression of virulence genes. J. Bacteriol. 1997, 179, 5777-5782. [CrossRef] [PubMed]

111. Anton, B.P.; Russell, S.P.; Vertrees, J.; Kasif, S.; Raleigh, E.A.; Limbach, P.A.; Roberts, R.J. Functional characterization of the YmcB and YqeV tRNA methylthiotransferases of Bacillus subtilis. Nucleic Acids Res. 2010, 38, 6195-6205. [CrossRef] [PubMed]

112. Arragain, S.; Handelman, S.K.; Forouhar, F.; Wei, F.Y.; Tomizawa, K.; Hunt, J.F.; Douki, T.; Fontecave, M.; Mulliez, E.; Atta, M. Identification of eukaryotic and prokaryotic methylthiotransferase for biosynthesis of 2-methylthio- $N^{6}$-threonylcarbamoyladenosine in tRNA. J. Biol. Chem. 2010, 285, 28425-28433. [CrossRef] [PubMed]

113. Persson, B.C.; Bjork, G.R. Isolation of the gene (MiaE) encoding the hydroxylase involved in the synthesis of 2-methylthio-cis-ribozeatin in tRNA of Salmonella typhimurium and characterization of mutants. J. Bacteriol. 1993, 175, 7776-7785. [CrossRef] [PubMed]

114. Mathevon, C.; Pierrel, F.; Oddou, J.L.; Garcia-Serres, R.; Blondin, G.; Latour, J.M.; Menage, S.; Gambarelli, S.; Fontecave, M.; Atta, M. tRNA-modifying MiaE protein from Salmonella typhimurium is a nonheme diiron monooxygenase. Proc. Natl. Acad. Sci. USA 2007, 104, 13295-13300. [CrossRef] [PubMed]

115. Lorsch, J. Methods in enzymology. Laboratory methods in enzymology: RNA. Preface. Methods Enzymol. 2013, 530, 21.

116. Cai, W.M.; Chionh, Y.H.; Hia, F.; Gu, C.; Kellner, S.; McBee, M.E.; Ng, C.S.; Pang, Y.L.; Prestwich, E.G.; Lim, K.S.; et al. A platform for discovery and quantification of modified ribonucleosides in RNA: Application to stress-induced reprogramming of tRNA modifications. Methods Enzymol. 2015, 560, 29-71. [PubMed]

117. Suzuki, T.; Ikeuchi, Y.; Noma, A.; Suzuki, T.; Sakaguchi, Y. Mass spectrometric identification and characterization of RNA-modifying enzymes. Methods Enzymol. 2007, 425, 211-229. [PubMed]

118. Chan, C.T.; Pang, Y.L.; Deng, W.; Babu, I.R.; Dyavaiah, M.; Begley, T.J.; Dedon, P.C. Reprogramming of tRNA modifications controls the oxidative stress response by codon-biased translation of proteins. Nat. Commun. 2012, 3, 937. [CrossRef] [PubMed]

119. Hossain, M.; Limbach, P.A. Mass spectrometry-based detection of transfer RNAs by their signature endonuclease digestion products. RNA 2007, 13, 295-303. [CrossRef] [PubMed] 
120. Heiss, M.; Kellner, S. Detection of nucleic acid modifications by chemical reagents. RNA Biol. 2016, 1-9. [CrossRef] [PubMed]

121. Caron, M.; Dugas, H. Specific spin-labeling of transfer ribonucleic acid molecules. Nucleic Acids Res. 1976, 3, 19-34. [CrossRef] [PubMed]

122. Yang, C.H.; Soll, D. Covalent attachment of a fluorescent group to 4-thiouridine in transfer RNA. J. Biochem. 1973, 73, 1243-1247. [CrossRef] [PubMed]

123. Gornicki, P.; Judek, M.; Wolanski, A.; Krzyzosiak, W.J. Hypermodified nucleoside carboxyl group as a target site for specific tRNA modification. Eur. J. Biochem. 1986, 155, 371-375. [CrossRef] [PubMed]

124. Pingoud, A.; Kownatzki, R.; Maass, G. Fluoresceinylthiocarbamyl-tRNATyr: A useful derivative of tRNATyr (E. coli) for physicochemical studies. Nucleic Acids Res. 1977, 4, 327-338. [CrossRef] [PubMed]

125. Yang, C.; Soll, D. Covalent attachment of fluorescent groups to transfer ribonucleic acid. Reactions with 4-bromomethyl-7-methoxy-2-oxo-2H-benzopyran. Biochemistry 1974, 13, 3615-3621. [CrossRef] [PubMed]

126. Kellner, S.; Seidu-Larry, S.; Burhenne, J.; Motorin, Y.; Helm, M. A multifunctional bioconjugate module for versatile photoaffinity labeling and click chemistry of RNA. Nucleic Acids Res. 2011, 39, 7348-7360. [CrossRef] [PubMed]

127. Igloi, G.L. Interaction of tRNAs and of phosphorothioate-substituted nucleic acids with an organomercurial. Probing the chemical environment of thiolated residues by affinity electrophoresis. Biochemistry 1988, 27, 3842-3849. [CrossRef] [PubMed]

128. Biondi, E.; Burke, D.H. Separating and analyzing sulfur-containing RNAs with organomercury gels. Methods Mol. Biol. 2012, 883, 111-120. [PubMed]

129. Kellner, S.; Burhenne, J.; Helm, M. Detection of RNA modifications. RNA Biol. 2010, 7, 237-247. [CrossRef] [PubMed]

130. Igloi, G.L.; Kossel, H. Affinity electrophoresis for monitoring terminal phosphorylation and the presence of queuosine in RNA. Application of polyacrylamide containing a covalently bound boronic acid. Nucleic Acids Res. 1985, 13, 6881-6898. [CrossRef] [PubMed]

131. Zaborske, J.M.; DuMont, V.L.; Wallace, E.W.; Pan, T.; Aquadro, C.F.; Drummond, D.A. A nutrient-driven tRNA modification alters translational fidelity and genome-wide protein coding across an animal genus. PLoS Biol. 2014, 12, e1002015. [CrossRef] [PubMed]

132. Cahova, H.; Winz, M.L.; Hofer, K.; Nubel, G.; Jaschke, A. NAD captureSeq indicates NAD as a bacterial cap for a subset of regulatory RNAs. Nature 2015, 519, 374-377. [CrossRef] [PubMed]

133. Damon, J.R.; Pincus, D.; Ploegh, H.L. tRNA thiolation links translation to stress responses in Saccharomyces cerevisiae. Mol. Biol. Cell 2015, 26, 270-282. [CrossRef] [PubMed]

134. Tyagi, K.; Pedrioli, P.G. Protein degradation and dynamic tRNA thiolation fine-tune translation at elevated temperatures. Nucleic Acids Res. 2015, 43, 4701-4712. [CrossRef] [PubMed]

135. Leidel, S.; Pedrioli, P.G.; Bucher, T.; Brost, R.; Costanzo, M.; Schmidt, A.; Aebersold, R.; Boone, C.; Hofmann, K.; Peter, M. Ubiquitin-related modifier Urm1 acts as a sulphur carrier in thiolation of eukaryotic transfer RNA. Nature 2009, 458, 228-232. [CrossRef] [PubMed]

136. Wohlgamuth-Benedum, J.M.; Rubio, M.A.; Paris, Z.; Long, S.; Poliak, P.; Lukes, J.; Alfonzo, J.D. Thiolation controls cytoplasmic tRNA stability and acts as a negative determinant for tRNA editing in mitochondria. J. Biol. Chem. 2009, 284, 23947-23953. [CrossRef] [PubMed]

137. Paris, Z.; Changmai, P.; Rubio, M.A.; Zikova, A.; Stuart, K.D.; Alfonzo, J.D.; Lukes, J. The Fe-S cluster assembly protein Isd11 is essential for tRNA thiolation in Trypanosoma brucei. J. Biol. Chem. 2010, 285, 22394-22402. [CrossRef] [PubMed]

138. Mishima, E.; Jinno, D.; Akiyama, Y.; Itoh, K.; Nankumo, S.; Shima, H.; Kikuchi, K.; Takeuchi, Y.; Elkordy, A.; Suzuki, T.; et al. Immuno-northern blotting: Detection of RNA modifications by using antibodies against modified nucleosides. PLoS ONE 2015, 10, e0143756. [CrossRef] [PubMed]

139. Gehrke, C.W.; Kuo, K.C.; McCune, R.A.; Gerhardt, K.O.; Agris, P.F. Quantitative enzymatic hydrolysis of tRNAs: Reversed-phase high-performance liquid chromatography of tRNA nucleosides. J. Chromatogr. 1982, 230, 297-308. [CrossRef]

140. Gehrke, C.W.; Kuo, K.C. Ribonucleoside analysis by reversed-phase high-performance liquid chromatography. J. Chromatogr. 1989, 471, 3-36. [CrossRef]

141. Alpert, A.J. Hydrophilic-interaction chromatography for the separation of peptides, nucleic acids and other polar compounds. J. Chromatogr. 1990, 499, 177-196. [CrossRef] 
142. Zhao, H.Q.; Wang, X.; Li, H.M.; Yang, B.; Yang, H.J.; Huang, L. Characterization of nucleosides and nucleobases in natural cordyceps by HILIC-ESI/TOF/MS and HILIC-ESI/MS. Molecules 2013, 18, 9755-9769. [CrossRef] [PubMed]

143. Dubin, D.T.; Gunalp, A. Minor nucleotide composition of ribosomal precursor, and ribosomal, ribonucleic acid in Escherichia coli. Biochim. Biophys. Acta 1967, 134, 106-123. [CrossRef]

144. Kowalak, J.A.; Bruenger, E.; McCloskey, J.A. Posttranscriptional modification of the central loop of domain V in Escherichia coli 23 S ribosomal RNA. J. Biol. Chem. 1995, 270, 17758-17764. [PubMed]

145. Johnson, J.D.; Horowitz, J. Characterization of ribosomes and RNAs from Mycoplasma hominis. Biochim. Biophys. Acta 1971, 247, 262-279. [CrossRef]

146. Emmerechts, G.; Barbe, S.; Herdewijn, P.; Anne, J.; Rozenski, J. Post-transcriptional modification mapping in the Clostridium acetobutylicum $16 \mathrm{~S}$ rRNA by mass spectrometry and reverse transcriptase assays. Nucleic Acids Res. 2007, 35, 3494-3503. [CrossRef] [PubMed]

147. Starr, J.L.; Fefferman, R. The occurrence of methylated bases in ribosomal ribonucleic acid of Escherichia coli K12 W-6. J. Biol. Chem. 1964, 239, 3457-3461. [PubMed]

148. Hayashi, Y.; Osawa, S.; Miura, K. The methyl groups in ribosomal RNA from Escherichia coli. Biochim. Biophys. Acta 1966, 129, 519-531. [CrossRef]

149. Morse, D.P.; Bass, B.L. Detection of inosine in messenger RNA by inosine-specific cleavage. Biochemistry 1997, 36, 8429-8434. [CrossRef] [PubMed]

150. Desrosiers, R.; Friderici, K.; Rottman, F. Identification of methylated nucleosides in messenger RNA from Novikoff hepatoma cells. Proc. Natl. Acad. Sci. USA 1974, 71, 3971-3975. [CrossRef] [PubMed]

151. Chionh, Y.H.; McBee, M.; Babu, I.R.; Hia, F.; Lin, W.; Zhao, W.; Cao, J.; Dziergowska, A.; Malkiewicz, A.; Begley, T.J.; et al. tRNA-mediated codon-biased translation in mycobacterial hypoxic persistence. Nat. Commun. 2016, 7, 13302. [CrossRef] [PubMed]

152. Su, D.; Ojo, T.T.; Soll, D.; Hohn, M.J. Selenomodification of tRNA in archaea requires a bipartite rhodanese enzyme. FEBS Lett. 2012, 586, 717-721. [CrossRef] [PubMed]

153. Basanta-Sanchez, M.; Temple, S.; Ansari, S.A.; D'Amico, A.; Agris, P.F. Attomole quantification and global profile of RNA modifications: Epitranscriptome of human neural stem cells. Nucleic Acids Res. 2016, 44, e26. [CrossRef] [PubMed]

154. Castleberry, C.M.; Limbach, P.A. Relative quantitation of transfer RNAs using liquid chromatography mass spectrometry and signature digestion products. Nucleic Acids Res. 2010, 38, e162. [CrossRef] [PubMed]

155. Ross, R.; Cao, X.; Yu, N.; Limbach, P.A. Sequence mapping of transfer RNA chemical modifications by liquid chromatography tandem mass spectrometry. Methods 2016, 107, 73-78. [CrossRef] [PubMed]

156. Chan, C.T.; Dyavaiah, M.; DeMott, M.S.; Taghizadeh, K.; Dedon, P.C.; Begley, T.J. A quantitative systems approach reveals dynamic control of tRNA modifications during cellular stress. PLoS Genet. 2010, 6, e1001247. [CrossRef] [PubMed]

157. Chan, C.T.; Deng, W.; Li, F.; DeMott, M.S.; Babu, I.R.; Begley, T.J.; Dedon, P.C. Highly predictive reprogramming of tRNA modifications is linked to selective expression of codon-biased genes. Chem. Res. Toxicol. 2015, 28, 978-988. [CrossRef] [PubMed]

158. Dedon, P.C.; Begley, T.J. A system of RNA modifications and biased codon use controls cellular stress response at the level of translation. Chem. Res. Toxicol. 2014, 27, 330-337. [CrossRef] [PubMed]

159. Su, D.; Chan, C.T.; Gu, C.; Lim, K.S.; Chionh, Y.H.; McBee, M.E.; Russell, B.S.; Babu, I.R.; Begley, T.J.; Dedon, P.C. Quantitative analysis of ribonucleoside modifications in tRNA by HPLC-coupled mass spectrometry. Nat. Protoc. 2014, 9, 828-841. [CrossRef] [PubMed]

160. Lipsett, M.N. Isolation of 4-thiouridylic acid from soluble ribonucleic acid of Escherichia coli. J. Biol. Chem. 1965, 240, 3975. [PubMed]

161. Cleary, M.D.; Meiering, C.D.; Jan, E.; Guymon, R.; Boothroyd, J.C. Biosynthetic labeling of RNA with uracil phosphoribosyltransferase allows cell-specific microarray analysis of mRNA synthesis and decay. Nat. Biotechnol. 2005, 23, 232-237. [CrossRef] [PubMed]

162. Palenchar, P.M.; Buck, C.J.; Cheng, H.; Larson, T.J.; Mueller, E.G. Evidence that ThiI, an enzyme shared between thiamin and 4-thiouridine biosynthesis, may be a sulfurtransferase that proceeds through a persulfide intermediate. J. Biol. Chem. 2000, 275, 8283-8286. [CrossRef] [PubMed]

163. Mueller, E.G.; Palenchar, P.M. Using genomic information to investigate the function of ThiI, an enzyme shared between thiamin and 4-thiouridine biosynthesis. Protein Sci. 1999, 8, 2424-2427. [CrossRef] [PubMed] 
164. Kuratani, M.; Yoshikawa, Y.; Bessho, Y.; Higashijima, K.; Ishii, T.; Shibata, R.; Takahashi, S.; Yutani, K.; Yokoyama, S. Structural basis of the initial binding of tRNA ${ }^{\text {Ile }}$ lysidine synthetase TilS with ATP and L-lysine. Structure 2007, 15, 1642-1653. [CrossRef] [PubMed]

165. Bender, R.A. The danger of annotation by analogy: Most "ThiI" genes play no role in thiamine biosynthesis. J. Bacteriol. 2011, 193, 4574-4575. [CrossRef] [PubMed]

166. Selbach, B.P.; Chung, A.H.; Scott, A.D.; George, S.J.; Cramer, S.P.; Dos Santos, P.C. Fe-S cluster biogenesis in Gram-positive bacteria: SufU is a zinc-dependent sulfur transfer protein. Biochemistry 2014, 53, 152-160. [CrossRef] [PubMed]

167. Liu, Y.; Vinyard, D.J.; Reesbeck, M.E.; Suzuki, T.; Manakongtreecheep, K.; Holland, P.L.; Brudvig, G.W.; Soll, D. A [3Fe-4S] cluster is required for tRNA thiolation in archaea and eukaryotes. Proc. Natl Acad. Sci. USA 2016. [CrossRef] [PubMed]

168. Liu, Y.; Zhu, X.; Nakamura, A.; Orlando, R.; Soll, D.; Whitman, W.B. Biosynthesis of 4-thiouridine in tRNA in the methanogenic archaeon Methanococcus maripaludis. J. Biol. Chem. 2012, 287, 36683-36692. [CrossRef] [PubMed]

169. Chowdhury, M.M.; Dosche, C.; Lohmannsroben, H.G.; Leimkuhler, S. Dual role of the molybdenum cofactor biosynthesis protein MOCS3 in tRNA thiolation and molybdenum cofactor biosynthesis in humans. J. Biol. Chem. 2012, 287, 17297-17307. [CrossRef] [PubMed]

170. Schmitz, J.; Chowdhury, M.M.; Hanzelmann, P.; Nimtz, M.; Lee, E.Y.; Schindelin, H.; Leimkuhler, S. The sulfurtransferase activity of Uba4 presents a link between ubiquitin-like protein conjugation and activation of sulfur carrier proteins. Biochemistry 2008, 47, 6479-6489. [CrossRef] [PubMed]

171. Umeda, N.; Suzuki, T.; Yukawa, M.; Ohya, Y.; Shindo, H.; Watanabe, K.; Suzuki, T. Mitochondria-specific RNA-modifying enzymes responsible for the biosynthesis of the wobble base in mitochondrial tRNAs. Implications for the molecular pathogenesis of human mitochondrial diseases. J. Biol. Chem. 2005, 280, 1613-1624. [CrossRef] [PubMed]

172. Nakai, Y.; Umeda, N.; Suzuki, T.; Nakai, M.; Hayashi, H.; Watanabe, K.; Kagamiyama, H. Yeast Nfs1p is involved in thio-modification of both mitochondrial and cytoplasmic tRNAs. J. Biol. Chem. 2004, 279, 12363-12368. [CrossRef] [PubMed]

173. Numata, T.; Ikeuchi, Y.; Fukai, S.; Suzuki, T.; Nureki, O. Snapshots of tRNA sulphuration via an adenylated intermediate. Nature 2006, 442, 419-424. [CrossRef] [PubMed]

174. Martin, H.L.; Black, K.A.; Dos Santos, P.C. Functional investigation of Bacillus subtilis YrkF's involvement in sulfur transfer reactions. Peptidomics 2015, 34, 54. [CrossRef]

175. Dahl, J.U.; Radon, C.; Buhning, M.; Nimtz, M.; Leichert, L.I.; Denis, Y.; Jourlin-Castelli, C.; Iobbi-Nivol, C.; Mejean, V.; Leimkuhler, S. The sulfur carrier protein TusA has a pleiotropic role in Escherichia coli that also affects molybdenum cofactor biosynthesis. J. Biol. Chem. 2013, 288, 5426-5442. [CrossRef] [PubMed]

176. Kozmin, S.G.; Stepchenkova, E.I.; Schaaper, R.M. Tusa (YhhP) and IscS are required for molybdenum cofactor-dependent base-analog detoxification. Microbiologyopen 2013, 2, 743-755. [CrossRef] [PubMed]

177. Nakayashiki, T.; Saito, N.; Takeuchi, R.; Kadokura, H.; Nakahigashi, K.; Wanner, B.L.; Mori, H. The tRNA thiolation pathway modulates the intracellular redox state in Escherichia coli. J. Bacteriol. 2013, 195, 2039-2049. [CrossRef] [PubMed]

178. Black, K.A.; Dos Santos, P.C. Shared-intermediates in the biosynthesis of thio-cofactors: Mechanism and functions of cysteine desulfurases and sulfur acceptors. Biochim. Biophys. Acta 2015, 1853, 1470-1480. [CrossRef] [PubMed]

179. Leimkuhler, S. The biosynthesis of the molybdenum cofactor in Escherichia coli and its connection to FeS cluster assembly and the thiolation of tRNA. Adv. Biol. 2014, 2014, 808569. [CrossRef]

180. Kambampati, R.; Lauhon, C.T. IscS is a sulfurtransferase for the in vitro biosynthesis of 4-thiouridine in Escherichia coli tRNA. Biochemistry 1999, 38, 16561-16568. [CrossRef] [PubMed]

181. Armengod, M.E.; Moukadiri, I.; Prado, S.; Ruiz-Partida, R.; Benitez-Paez, A.; Villarroya, M.; Lomas, R.; Garzon, M.J.; Martinez-Zamora, A.; Meseguer, S.; et al. Enzymology of tRNA modification in the bacterial mnmeg pathway. Biochimie 2012, 94, 1510-1520. [CrossRef] [PubMed]

182. Moukadiri, I.; Garzon, M.J.; Bjork, G.R.; Armengod, M.E. The output of the tRNA modification pathways controlled by the Escherichia coli MnmEG and MnmC enzymes depends on the growth conditions and the tRNA species. Nucleic Acids Res. 2014, 42, 2602-2623. [CrossRef] [PubMed] 
183. Mihara, H.; Kato, S.; Lacourciere, G.M.; Stadtman, T.C.; Kennedy, R.A.; Kurihara, T.; Tokumoto, U.; Takahashi, Y.; Esaki, N. The IscS gene is essential for the biosynthesis of 2-selenouridine in tRNA and the selenocysteine-containing formate dehydrogenase H. Proc. Natl. Acad. Sci. USA 2002, 99, 6679-6683. [CrossRef]

184. Bartos, P.; Maciaszek, A.; Rosinska, A.; Sochacka, E.; Nawrot, B. Transformation of a wobble 2-thiouridine to 2-selenouridine via S-geranyl-2-thiouridine as a possible cellular pathway. Bioorg. Chem. 2014, 56, 49-53. [CrossRef] [PubMed]

185. Lacourciere, G.M.; Mihara, H.; Kurihara, T.; Esaki, N.; Stadtman, T.C. Escherichia coli NifS-like proteins provide selenium in the pathway for the biosynthesis of selenophosphate. J. Biol. Chem. 2000, 275, 23769-23773. [CrossRef] [PubMed]

186. Edmonds, C.G.; Crain, P.F.; Gupta, R.; Hashizume, T.; Hocart, C.H.; Kowalak, J.A.; Pomerantz, S.C.; Stetter, K.O.; McCloskey, J.A. Posttranscriptional modification of tRNA in thermophilic archaea (archaebacteria). J. Bacteriol. 1991, 173, 3138-3148. [CrossRef] [PubMed]

187. McCloskey, J.A.; Graham, D.E.; Zhou, S.; Crain, P.F.; Ibba, M.; Konisky, J.; Soll, D.; Olsen, G.J. Post-transcriptional modification in archaeal tRNAs: Identities and phylogenetic relations of nucleotides from mesophilic and hyperthermophilic methanococcales. Nucleic Acids Res. 2001, 29, 4699-4706. [CrossRef] [PubMed]

188. Cabello-Villegas, J.; Winkler, M.E.; Nikonowicz, E.P. Solution conformations of unmodified and $\mathrm{A}_{37} \mathrm{~N}^{6}$-dimethylallyl modified anticodon stem-loops of Escherichia coli tRNA ${ }^{\text {Phe }}$. J. Mol. Biol. 2002, 319, 1015-1034. [CrossRef]

189. Lamichhane, T.N.; Mattijssen, S.; Maraia, R.J. Human cells have a limited set of tRNA anticodon loop substrates of the tRNA isopentenyltransferase Trit1 tumor suppressor. Mol. Cell. Biol. 2013, 33, 4900-4908. [CrossRef] [PubMed]

190. Lamichhane, T.N.; Blewett, N.H.; Maraia, R.J. Plasticity and diversity of tRNA anticodon determinants of substrate recognition by eukaryotic A37 isopentenyltransferases. RNA 2011, 17, 1846-1857. [CrossRef] [PubMed]

191. Lin, C.A.; Ellis, S.R.; True, H.L. The Sua5 protein is essential for normal translational regulation in yeast. Mol. Cell. Biol. 2010, 30, 354-363. [CrossRef] [PubMed]

192. Kimura, S.; Suzuki, T. Iron-sulfur proteins responsible for RNA modifications. Biochim. Biophys. Acta 2015, 1853, 1272-1283. [CrossRef] [PubMed]

193. Deutsch, C.; El Yacoubi, B.; de Crecy-Lagard, V.; Iwata-Reuyl, D. Biosynthesis of threonylcarbamoyl adenosine $\left(\mathrm{t}^{6} \mathrm{~A}\right)$, a universal tRNA nucleoside. J. Biol. Chem. 2012, 287, 13666-13673. [CrossRef] [PubMed]

194. Thiaville, P.C.; El Yacoubi, B.; Perrochia, L.; Hecker, A.; Prigent, M.; Thiaville, J.J.; Forterre, P.; Namy, O.; Basta, T.; de Crecy-Lagard, V. Cross kingdom functional conservation of the core universally conserved threonylcarbamoyladenosine tRNA synthesis enzymes. Eukaryot. Cell 2014, 13, 1222-1231. [CrossRef] [PubMed]

195. Harris, K.A.; Bobay, B.G.; Sarachan, K.L.; Sims, A.F.; Bilbille, Y.; Deutsch, C.; Iwata-Reuyl, D.; Agris, P.F. NMR-based structural analysis of threonylcarbamoyl-AMP synthase and its substrate interactions. J. Biol. Chem. 2015, 290, 20032-20043. [CrossRef] [PubMed]

196. Trotter, V.; Vinella, D.; Loiseau, L.; Ollagnier de Choudens, S.; Fontecave, M.; Barras, F. The CsdA cysteine desulphurase promotes $\mathrm{Fe} / \mathrm{S}$ biogenesis by recruiting suf components and participates to a new sulphur transfer pathway by recruiting CsdL (ex-YgdL), a ubiquitin-modifying-like protein. Mol. Microbiol. 2009, 74, 1527-1542. [CrossRef] [PubMed]

197. Bauerle, M.R.; Schwalm, E.L.; Booker, S.J. Mechanistic diversity of radical S-adenosylmethionine (SAM)-dependent methylation. J. Biol. Chem. 2015, 290, 3995-4002. [CrossRef] [PubMed]

198. Booker, S.J.; Grove, T.L. Mechanistic and functional versatility of radical SAM enzymes. F1000 Biol. Rep. 2010, 2, 52. [CrossRef] [PubMed]

199. Booker, S.J. Radical sam enzymes and radical enzymology. Biochim. Biophys. Acta 2012, 1824, 1151-1153. [CrossRef] [PubMed]

200. Landgraf, B.J.; McCarthy, E.L.; Booker, S.J. Radical S-adenosylmethionine enzymes in human health and disease. Annu. Rev. Biochem. 2016, 85, 485-514. [CrossRef] [PubMed] 
201. Kaminska, K.H.; Baraniak, U.; Boniecki, M.; Nowaczyk, K.; Czerwoniec, A.; Bujnicki, J.M. Structural bioinformatics analysis of enzymes involved in the biosynthesis pathway of the hypermodified nucleoside $\mathrm{ms}^{2} \mathrm{io}^{6} \mathrm{~A} 37$ in tRNA. Proteins 2008, 70,1-18. [CrossRef] [PubMed]

202. Anton, B.P.; Saleh, L.; Benner, J.S.; Raleigh, E.A.; Kasif, S.; Roberts, R.J. Rimo, a MiaB-like enzyme, methylthiolates the universally conserved Asp88 residue of ribosomal protein S12 in Escherichia coli. Proc. Natl. Acad. Sci. USA 2008, 105, 1826-1831. [CrossRef] [PubMed]

203. Lee, K.H.; Saleh, L.; Anton, B.P.; Madinger, C.L.; Benner, J.S.; Iwig, D.F.; Roberts, R.J.; Krebs, C.; Booker, S.J. Characterization of RimO, a new member of the methylthiotransferase subclass of the radical SAM superfamily. Biochemistry 2009, 48, 10162-10174. [CrossRef] [PubMed]

204. Agris, P.F.; Armstrong, D.J.; Schafer, K.P.; Soll, D. Maturation of a hypermodified nucleoside in transfer RNA. Nucleic Acids Res. 1975, 2, 691-698. [CrossRef]

205. Lanz, N.D.; Booker, S.J. Auxiliary iron-sulfur cofactors in radical SAM enzymes. Biochim. Biophys. Acta 2015, 1853, 1316-1334. [CrossRef] [PubMed]

(c) 2017 by the authors. Licensee MDPI, Basel, Switzerland. This article is an open access article distributed under the terms and conditions of the Creative Commons Attribution (CC BY) license (http:/ / creativecommons.org/licenses/by/4.0/). 